\title{
Insight into seismic refraction and electrical resistivity tomography techniques in subsurface investigations
}

The Mining-Geology-Petroleum Engineering Bulletin UDC: 550.3

DOI: 10.17794/rgn.2019.1.9

Review professional paper

\author{
Adedibu Sunny Akingboye; Abimbola Chris Ogunyele \\ Department of Earth Sciences, Adekunle Ajasin University, P.M.B. 001, Akungba-Akoko, Ondo State, Nigeria
}

\begin{abstract}
Geophysical subsurface investigations use the principles of physics to unravel intrinsic Earth's subsurface features and nature of the underlying geology. Over the past two decades, the use of Seismic Refraction Tomography (SRT) and Electrical Resistivity Tomography (ERT) for subsurface investigations has greatly improved the quality of acquired data for two- and three-dimensional (2D and $3 \mathrm{D})$ surveys. SRT employs more shotpoints and receivers than the conventional seismic refraction for its imaging technique. ERT uses automated multi-electrode array systems to improve the confidence of large and dense data collection. SRT and ERT techniques use powerful inversion algorithms to achieve high resolution subsurface inversion models for resolving subsurface characteristics and geological conditions over a complex and larger area that may be difficult with the use of their conventional methods. The $2 \mathrm{D}$ and $3 \mathrm{D}$ inversion models (tomograms) generated from the field data sets of these techniques efficiently ameliorate inaccurate subsurface boundaries and structural delineation with higher depth resolution, especially the $3 \mathrm{D}$ inversion models for areas of complex geology. These state-of-the-art techniques have extensively been used for groundwater, environmental, engineering and mining investigations among others. This study provides insight from theories to data inversion techniques for the known tomography techniques (SRT and ERT) in use for subsurface investigations.
\end{abstract}

\section{Keywords:}

Seismic Refraction Tomography (SRT); Electrical Resistivity Tomography (ERT); field designs; multi-electrode array; inversion models.

\section{Introduction}

Geophysical methods employ the principles of physics to image intrinsic Earth's subsurface features that are diagnostic of some targeted points. Subsurface characterisation for underground resources, pollution-free environments, and understanding the effects of subsurface geological conditions have led to the advancements in geophysical imaging methods used for such investigations (Griffiths and Barker, 1993, 1994; Mwenifumbo, 1997; Pellerin, 2002; Quigley, 2006; Colangelo et al., 2008; Rucker et al., 2010; Ayolabi et al., 2012; Berry, 2013; Loke et al., 2013; Arjwech and Everett, 2015; Akingboye, 2018).

The characterisation of subsurface geology using only intrusive geotechnical exploration techniques, such as soil borings, rock coring, and one-dimensional (1D) geophysical investigation like vertical electrical sounding (VES) and borehole logging are extremely limited because these techniques provide information regarding the subsurface only at the specific location surveyed and may not be reliable for interpreting the surrounding con-

Corresponding author: Adedibu Sunny Akingboye adedibu.akingboye@aaua.edu.ng ditions with lateral variations (Quigley, 2006). Thus, seismic refraction and electrical resistivity are the most widely used geophysical methods for determining reliable subsurface information both laterally and vertically about an area investigated.

Seismic refraction was the earliest and principal geophysical method employed in the search for hydrocarbon-bearing structures. Hydrocarbon exploration now depend mostly on varieties of seismic reflection methods today, but seismic refraction is seldom in use for resolving complex structures associated with hydrocarbon exploration (Bery, 2013). Over the years, the seismic refraction method has been used increasingly in near-surface geophysical investigations (Carpenter et al., 2003; Cramer and Hiltumen, 2004; Hiltumen and Cramer, 2006; Bery and Saad, 2012a, b). Seismic methods can clearly map undulating interfaces and demarcate boundary conditions, but without using cutting-edge data processing techniques the methods will have difficulty in some geophysical conditions such as mapping of discrete bodies like boulders, cavities and pollution plume (Loke, 2002). In recent times, Seismic Refraction Tomography (SRT) has served as that cutting-edge technique which provides more details about the subsurface over a much larger area than the conventional methods by using more 
shotpoints and complex mathematic algorithms to fit a more flexible model to produce a high resolution subsurface profile (Azwin et al., 2013; Bery, 2013).

Electrical resistivity method was principally and commercially used since the early 1920 's to the late 1980 's as a 1D imaging method, but when it comes to resolving complex subsurface geology, the method is not sufficiently accurate (Burger et al., 2006; Loke et al., 2013). Over the last two decades, the development of multi-electrode arrays, automated acquisition systems, and new inversion algorithms used for Electrical Resistivity Tomography (ERT) have been sufficiently versatile in resolving complex subsurface geology. ERT technique is a recent advancement in electrical resistivity imaging that offer non-invasive measurements for subsurface characterisation at various scales with better resolution over its conventional method, especially the 3D ERT surveys that produce better subsurface resolution in complex geological areas. Also, development of four-dimensional (4D) survey and 4D inversion technique has been proposed for solving, monitoring and deriving more details in such areas (Loke, 2004; Kim et al., 2009; Loke et al., 2013).

SRT and ERT techniques have been used to investigate volcanic and geothermal areas, landslides, seismotectonic structures, hydrogeological phenomena, environmental problems as well as the deposition and flow of impact melt and breccia (Griffiths and Barker, 1993; Steeples, 2001; Lapenna et al., 2005; Quigley, 2006; Colangelo et al., 2008; Tong et al., 2010). Besides their enormous uses and advantages, these techniques have helped to reduce cost through their fast field data acquisition and wide area coverage, as well as better derivable subsurface features of higher resolution over their conventional methods. However, the versatilities of these state-of-the-art techniques which are tied to data acquisitions (surveys), inversions and interpretations demand considerable practical experience of the methods on one hand, and on the other hand, sound knowledge of the geology of the region under investigation.

This paper highlights the theories, field data acquisitions, inversion techniques, merits and limitations of SRT and ERT techniques in subsurface investigations.

\section{Seismic refraction tomography}

Seismic refraction method measures the traveltimes of seismic waves refracted at the interfaces between subsurface layers of different velocities. The development of powerful computer technology used for earthquake location and in the determination of seismic body waves traveltimes from near surface to deep earth's interior led to the modern field of seismic tomography, a powerful technique for determination of depths and velocities of overburden constituents and the refractors within the Earth's subsurface (Telford et al., 1990; Kearey et al., 2002; Quigley, 2006).
Seismic refraction tomography also known as "velocity gradient or diving-wave tomography" is an imaging technique that produces a cross-sectional picture (tomogram/inverted velocity model) of the subsurface through response to non-destructive probing energy from external source such as hammer blow, little amount of dynamite of less energy, weight drop, etc (Zhu and McMechan, 1989; Stefani, 1995; Tien-When and Philip, 1994). The conventional seismic refraction data processing is deficient of showing the true strength of subsurface earth materials because it uses overgeneralised geometry for breaking model into continuous layers of constant velocity, whereas SRT does not require that the model has to be broken into constant velocity continuous layers, but has to be made up of a high number of small constant velocity grid cells or nodes (Zhang and Toksoz, 1998). The model is inverted by performing ray tracing, through an initial model and comparing the modelled traveltimes to the field data, and adjusting the model grid-by-grid in order to match the calculated traveltimes to the field data, so as to generate the resulting subsurface velocity model also known as tomogram/inverted velocity model after the number of program predefined iterations has been completed (Gregory, 2002; Sheehan et al., 2005a).

SRT technique is mainly used for mapping of weathered layer, depth to water table, basement structures for engineering purposes, and applying correction to reflection data (Osemeikhian and Asokhia, 1994). The information derived from SRT may be used to predict spatial variations in lithology, pore fluids, or rock fracturing. It can also be applied on a variety of spatial scales, from ranges of hundreds of metres, down to engineering or archaeological investigations of single columns in ancient buildings, as well as resolving velocity gradients, lateral velocity changes within the subsurface with greater ability and for modelling localised velocity anomalies (Cardarelli and de Nardis, 2001). In addition, SRT may be applied in geologic settings where conventional refraction method fails, such as areas of compaction, karst, and zone faults, as well as in areas with extreme topography or complex near-surface structures where the user has little or no prior knowledge of subsurface structures (Dutta, 1984; Zhang and Toksoz, 1998; Azwin et al., 2013), and in areas with serious limitations in spread length.

\subsection{Seismic refraction tomography field data acquisition}

In the field procedure, SRT makes use of the same data acquisition equipment but requires more shotpoints and receivers than the conventional seismic refraction. The data acquisition equipment consists some of the following units:

i. Energy Source - this could be hammer blow and metallic plate, weight drop or explosive charge (in small quantity) for generating and transmitting seismic waves into the subsurface. 


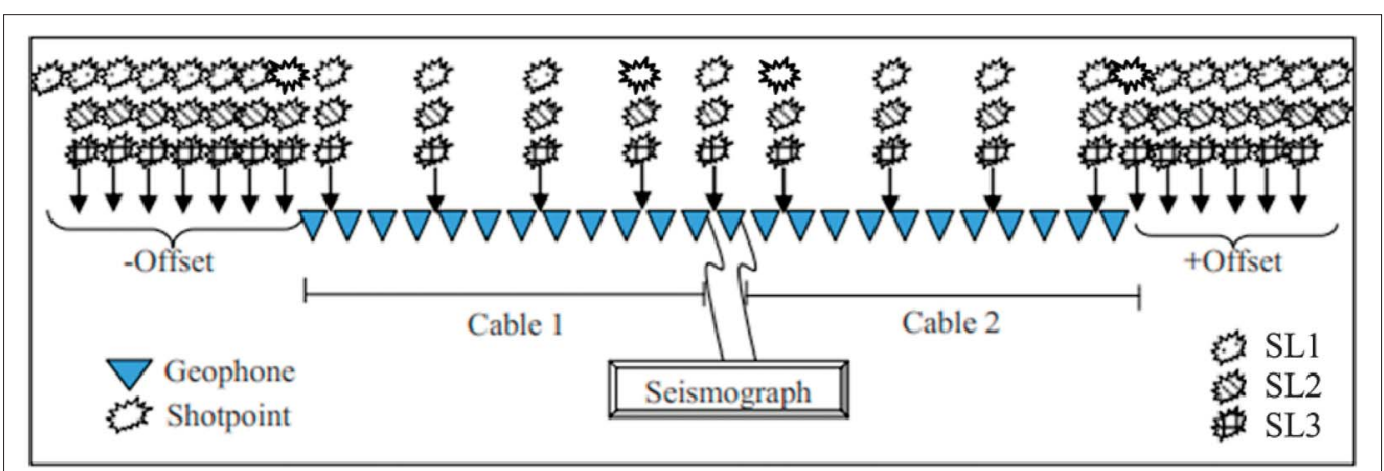

(a)

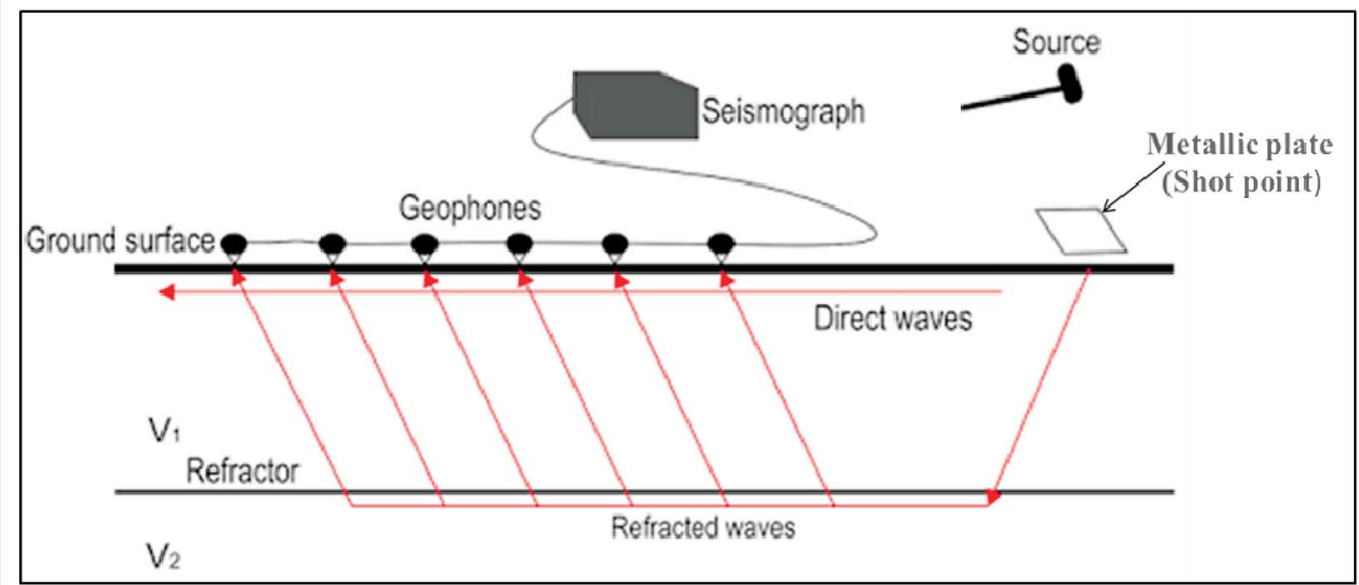

(b)

Figure 1: (a) A typical SRT data acquisition layout showing channel of geophones, geophones' cables connected to seismograph, and location of shotpoints for every survey line (SL) (modified after Azwin et al., 2013). (b) Instrumentation and progression of seismic waves (compression or P-waves) generated at the surface and refracted at boundary surfaces during SRT data acquisition).

ii. Geophones (Receiver) - are electrochemical transducers that convert ground motion into an electrical analog signal. A channel of geophones is used to detect arrival times (compression or P-wave) emanating from subsurface features. The geophones are rightly positioned using GPS and metre rule.

iii. Geophone Cables - to transmit analog electrical impulses from geophones to seismograph.

iv. Seismograph - it is housed in the measuring unit for recording the information detected by geophones on channel dynamic signal analyser.

v. Laptop - to dump field data for data analysis and processing.

SRT data acquisition employs sufficient shotpoints at different survey lines at the Earth's surface to obtain high quality seismic data. Figure 1a shows a typical SRT data acquisition layout consisting channel of geophones, geophones' cables connected to a seismograph, and a location of shotpoints for every survey line (SL). The survey line can be one or more depending on the traverse length, geometry of target point, and depth of investigation. Along the offsets, more clusters of shotpoints are required due to the distance between every shot and geophone for high signal-to-noise ratio and deeper depth resolution, unlike shotpoints that are taken where the geophones are laid. The particular depth of interest can be probed by increasing the energy source at shotpoints. When the refractor is suspected to have a dip, the velocities of the beds and the dip of the interface can be obtained by shooting a second complementary profile in the opposite direction (Kearey et al., 2002). Figure 1b shows the instrumentation and progression of generated seismic P-waves through the subsurface and how they are refracted at boundary surfaces where changes in acoustic impedance occur during SRT data acquisition. However, some of the generated seismic waves are reflected at boundary surfaces while others do not travel through the subsurface but travel directly to the geophones as direct waves. The inversion software is therefore used for picking the first arrival times (compression or P-wave) through visual inspection from collected time record.

\subsection{Seismic refraction tomography data inversion processes}

The commercially available SRT software includes Rayfract, SeisImager, SeisOpt, Reflex, Accelerometer, 
First-PIX and GREMIX15 among others. The SRT software has a system interface (protocol) for picking first arrival time (compression or P-wave) and inverting processes to get the final inverted model for interpretation. Some of the most commonly used inversion software such as Rayfract, SeisImager and SeisOpt will be discussed in this work.

The Rayfract uses the wave path eikonal traveltime (WET) inversion method in its tomography processing. WET inversion computes wave paths through finite-difference solutions to the eikonal equation by using the Fresnel volume approach that takes into account the effects that the real waves have on the adjacent parts of the model taking longer traveltimes as an alternative to the ray path approach used by most programs. The WET inversion method is able to account for effects such as shadow zones and multi-pathing effects (Qin et al., 1992; Schuster et al., 1993; Sheehan et al., 2005b). Rayfract uses the inversion method of Delta $t-v$ or smooth to generate an initial model. The Delta t-v method is useful in identifying small features and velocity inversions. The disadvantage of using the Delta $t-v$ method for initial output is that there may be artifacts in the output model and are not completely removed by subsequent inversion (Sheehan et al., 2005b). The smooth inversion method is recommended as a fail-safe method for producing an initial model. The smooth inversion method eliminates the effects of artifacts caused by a strong refractor curvature and lateral variations in the initial model to finally generate a final tomogram that accurately models the subsurface features. However, the ability to image velocity variations and vertical resolutions is somewhat decreased in the smooth inversion method (Intelligent Resources Inc., 2006).

The SeisImager has a system package for picking the first arrival time (compression or P-wave) known as the PICKWin program. SeisImager uses nonlinear traveltime tomography consisting of ray tracing for forward modelling and simultaneous iterative reconstruction technique (SIRT) for inversion. The main features of the algorithm are: an initial model is constructed so that the velocity is layered and increased with depth, the first arrival traveltimes and ray paths are calculated by the ray tracing method based on the shortest path calculation as described by Moser (1991), and a traveltime between a source and a receiver is defined as the fastest traveltime of all ray paths, the model is updated by SIRT and the velocity of each cell is updated during the iterations (Hayashi and Takahashi, 2001).

SeisOpt Pro avoids ray tracing and uses non-linear optimisation, namely generalised simulated annealing, to invert the first arrival traveltimes for shallow velocities making it independent of the initial model. This accounts for curved rays and all types of primary arrivals (Pullammanappallil and Louie, 1994). For the forward model, it employs a fast finite-difference scheme based on a solution to the eikonal equation which computes first arrival traveltimes through the velocity model (Vidale, 1988). Traveltime inversions that use linearised inversions do not take into account changes in the velocity field due to ray paths, making them initial model dependent, which could cause them to converge at an incorrect solution.

The stages involved in SRT inversion processes are given below and the flow chart is shown in Figure 2.

i. The field data format is renamed/converted to readable file format of the software to be used for the data analysis and processing.

ii. Gain control is applied to the data to accentuate weak arrival times and other wavelets to improve the quality of the wavelet traces when to be picked.

iii. First arrival times (compression or P-wave) are manually picked through visual inspection from collected time record on software program like PickWin and saved for subsequent analysis. All picked first arrival times are summed and averaged. Values below the average time are classified to be from the first layer, while those that are higher than the average time are considered to have been refracted from the second layer.

iv. A traveltime curve is generated through the layer assignment technique in interpretation module like PlotRefa.

v. The model is divided into a large number of smaller constant velocity grid cells or nodes. The model is then inverted by performing ray tracing with the grid cells adjusted in an attempt to match the calculated travel times to produce a 2D initial model.

vi. This is repeated until the number of pre-defined iterations within the program has been completed, with the resulting final subsurface velocity model/ tomogram, being produced upon completion.

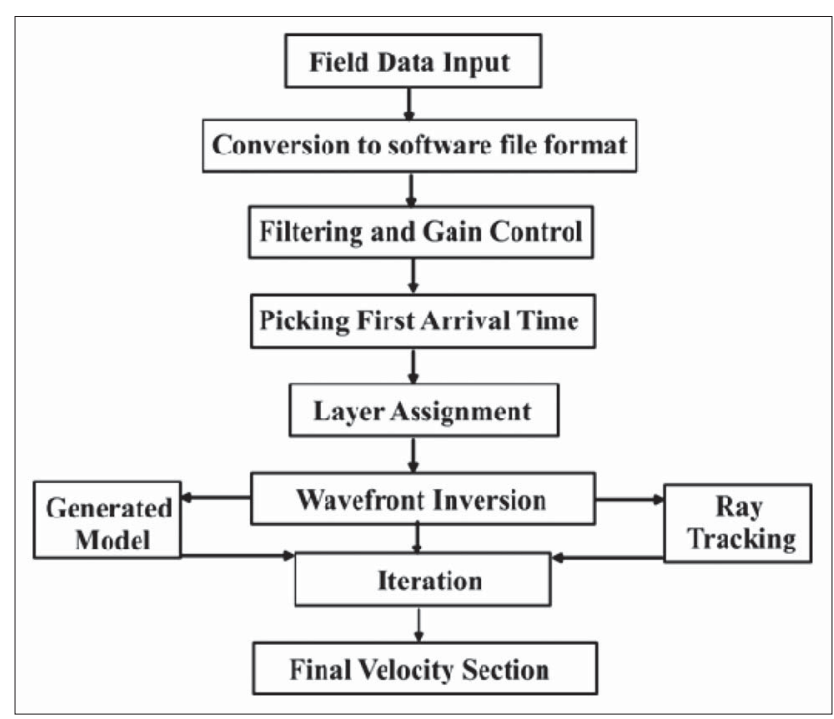

Figure 2: Seismic refraction tomography data processing flow chart. 


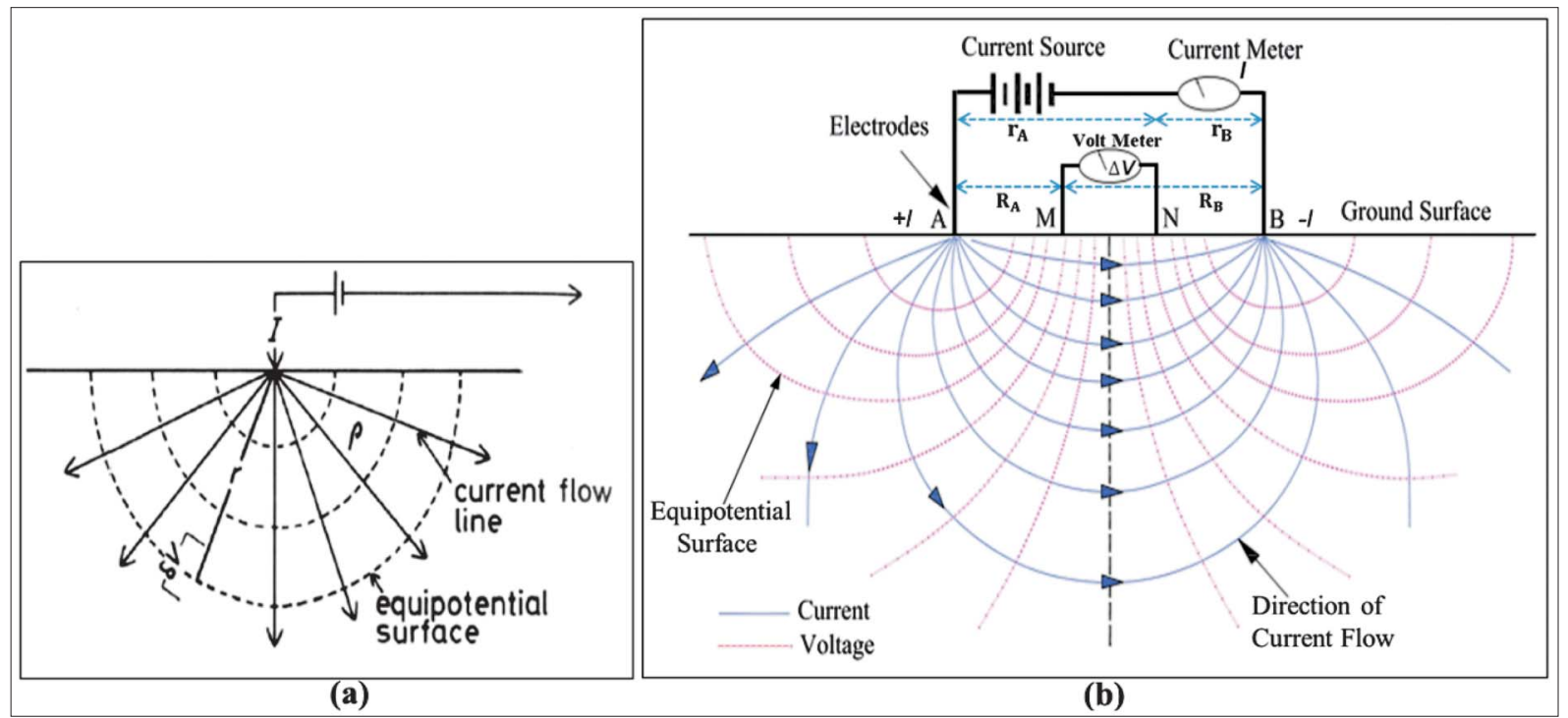

Figure 3: (a) Current flow from a single point source electrode (Kearey et al., 20o2) and, (b) fundamental concepts of resistivity measurements (modified after Todd and Mays, 1980).

\section{An overview of electrical resistivity method}

There are many methods of electrical surveying; some use fields within the earth while others require artificially generated currents to be introduced into the earth's subsurface. The electrical resistivity method uses artificially generated currents from surface electrodes. Electrical resistivity method is performed to determine the electrical resistivity $(\rho)$ of the subsurface. The relationship between the electrical current $(I)$, resistance of the conductor $(R)$ and the potential difference $(V)$ across the conductor is based on Ohm's law. It is from this law that the fundamental principle used for data acquisition and interpretation of resistivity measurement originated from. Ohm's law is represented mathematically as:

$$
V=I R
$$

Equation 1 can further be expressed by considering the geometry of a wire, which is typically cylindrical with length, $L(\mathrm{~m})$, cross-sectional area, $a\left(\mathrm{~m}^{2}\right)$, and resistance, $R(\Omega)$. The total resistance of the wire element, $R$ is given by Equation 2:

$$
R=\rho \frac{L}{A}
$$

Equation 2 can be re-written as:

$$
\rho=R \frac{A}{L}
$$

For a single current electrode on the surface of the earth of uniform resistivity $(\rho)$ (see Figure 3a), the current flows radially away from the electrode into the earth so that the current distribution is uniform over hemispherical shells centred on the source (Telford et al., 1990; Kearey et al., 2002). At a distance ( $r$ ) from the electrode, the hemispherical shell has a surface area, $A=2 \pi r^{2}$, so the current density $(j)$ is given by:

$$
j=\frac{I}{A}=\frac{I}{2 \pi r^{2}}
$$

But, $J=\frac{E}{\rho}$; where $E$ is the electric field, or the gradient of a scalar potential.

$$
E=-\nabla V
$$

The potential gradient associated with this current density $(j)$ is:

$$
\nabla V=-\rho j=-\frac{\rho I}{2 \pi r^{2}}
$$

The potential is then obtained by integration:

$$
V_{r}=\int \nabla V=-\int \frac{\rho I \partial r}{2 \pi r^{2}}=\frac{\rho I}{2 \pi r}
$$

Equation 7 is used for calculating the potential difference at the surface or below the surface of a homogeneous half-space.

Figure 3b shows the fundamental concepts of resistivity measurements using electrode configuration of a pair of current electrodes $(A, B)$ and a pair of potential electrodes $(M, N)$. In this case, the current is a finite distance from the source. The potential $V_{M}$ at an internal electrode $M$ is the sum of the potential contributions $V_{A}$ and $V_{B}$ from the current source at $A(+v e)$ and the sink at $B$ (-ve). Therefore, Equation 8 is given as:

$$
V_{M}=V_{A}+V_{B}
$$

From Equation 7:

$$
V_{M}=\frac{\rho I}{2 \pi}\left(\frac{1}{r_{A}}-\frac{1}{r_{B}}\right)
$$




$$
\text { Similarly, } V_{N}=\frac{\rho I}{2 \pi}\left(\frac{1}{R_{A}}-\frac{1}{R_{B}}\right)
$$

Therefore, potential difference $\Delta V$ between electrodes $M$ and $N$ is given as:

$$
\begin{gathered}
\Delta V=V_{M}-V_{N}=\frac{\rho I}{2 \pi}\left\{\left(\frac{1}{r_{A}}-\frac{1}{r_{B}}\right)-\left(\frac{1}{R_{A}}-\frac{1}{R_{B}}\right)\right\} \\
\rho=\frac{2 \pi \Delta V}{\left.I\left(\frac{1}{r_{A}}-\frac{1}{r_{B}}\right)-\left(\frac{1}{R_{A}}-\frac{1}{R_{B}}\right)\right)}
\end{gathered}
$$

$k$ is the geometric factor of the array and it is written mathematically as:

$$
k=\frac{2 \pi}{\left.\left(\frac{1}{r_{A}}-\frac{1}{r_{B}}\right)-\left(\frac{1}{R_{A}}-\frac{1}{R_{B}}\right)\right)}
$$

But, $R=\frac{\Delta V}{I}$

The apparent resistivity can be re-written: $\rho_{a}=k R$

The wide range of resistivity values for earth materials has been the essential reason why ERT technique can be used for different applications (Loke, 2002; Bernard, 2003). Table 1 shows the range of resistivity values for some earth materials.

\subsection{Configurations and sensitivities of electrode arrays}

The arrangement of electrodes relative to one another is referred to as array configuration. The array types are: Wenner, Schlumberger, dipole-dipole, gradient, polepole, pole-dipole and squared array, etc (Loke, 2002). Some of these arrays make use of a pair of current and potential electrodes, while just a few employ either a single current or potential electrode for imaging the lateral and vertical variations in electrical properties of earth materials, as well as detecting $2 \mathrm{D}$ and $3 \mathrm{D}$ anomalous bodies (Griffiths et al., 1990; Telford et al., 1990; Griffiths and Barker, 1993; Reynolds 1997, 2011; Kearey et al., 2002; Merritt, 2014). The configurations of some of the arrays in use and their sensitivities to lateral and vertical variations are shown in Figures 4a-j.

i. The Wenner array is of three configuration types, which are: Wenner-Alpha $(\alpha)$ with configuration $C 1$ P1 P2 C2 (see Figure 4a), Wenner-Beta $(\beta)$ with configuration $C 2 C 1 P 1 P 2$ (see Figure 4b), and Wenner-Gamma $(\gamma)$ with configuration $C l P l$ $C 2 P 2$ (see Figure 4c). Wenner arrays are highly sensitive to vertical changes in resistivity below the centre of the array, but less sensitive to lateral/ horizontal resistivity changes like sills and sedimentary structures (Merritt 2014). Therefore, they may be considered best for a noisy area and for deriving good vertical resolution (Loke 2002).

ii. The Schlumberger array is similar to the Wenner- $\alpha$ array, both having similar electrodes positions as $C 1 P 1 P 2 C 2$ but $P 1 P 2$ are closely spaced (see Figure 4d). This hybrid of Wenner array has slightly better horizontal coverage compared to the Wenner- $\alpha$ array. However, its horizontal coverage is narrower than the dipole-dipole array. When using Schlumberger array for any survey, the area of interest must be carefully selected because it is sensitive to conditions around the closely spaced inner electrodes (Loke, 2002; Ewusi, 2006; Merritt, 2014).

iii. The pole-pole array is not as commonly used as the others arrays. Pole-pole array is configured as $C 1 P 1$ while both $C 2$ and $P 2$ electrodes must be placed at distances which are more than 20 times the separation between $C 1$ and $P 1$ (see Figure 4e). This array has the widest horizontal coverage and the deepest depth of investigations. However, the quality of acquired data is greatly reduced by telluric noise that is picked up due to large separa-

Table 1: Typical electrical resistivity values for some earth materials (Loke 20o2; Gibson and George 2003; Society of Exploration Geophysicist of Japan (SEGJ) 2004; Advanced Geosciences Incorporated (AGI) 2008 ).

\begin{tabular}{|l|c|c|c|c|c|}
\hline \multirow{2}{*}{\begin{tabular}{l} 
Materials \\
\cline { 2 - 6 }
\end{tabular}} & Loke (2002) & $\begin{array}{c}\text { Gibson and George } \\
\mathbf{( 2 0 0 3 )}\end{array}$ & SEGJ (2004) & Ewusi (2006) & AGI (2008) \\
\hline Clay & $1-100$ & $1-100$ & $1-300$ & $1-100$ & $10-100$ \\
\hline Sand & $10-800$ & $50-1050$ & $1-1100$ & $30-1050$ & $600-1 \times 10^{4}$ \\
\hline Lateritic Soil & ---- & ---- & --- & $120-750$ & ---- \\
\hline Gravel & $600-10^{4}$ & $100-1400$ & $20-7000$ & $100-1400$ & $600-1 \times 10^{4}$ \\
\hline Mudstone & ---- & ---- & ---- & $20-120$ & ---- \\
\hline Siltstone & ---- & --- & --- & $20-150$ & $100-1 \times 10^{6}$ \\
\hline Limestone & $80-6000$ & $50-10^{6}$ & ---- & --- & --- \\
\hline Shale & $20-2000$ & --- & $3-200$ & $20-2 \times 10^{3}$ & $100-1 \times 10^{3}$ \\
\hline Sandstone & $10-5000$ & $1-7.4 \times 10^{8}$ & $10-700$ & $200-5000$ & ---- \\
\hline Granite & $5000-10^{6}$ & $100-10^{6}$ & $300-40000$ & $3 \times 10^{2}-10^{6}$ & \\
\hline
\end{tabular}




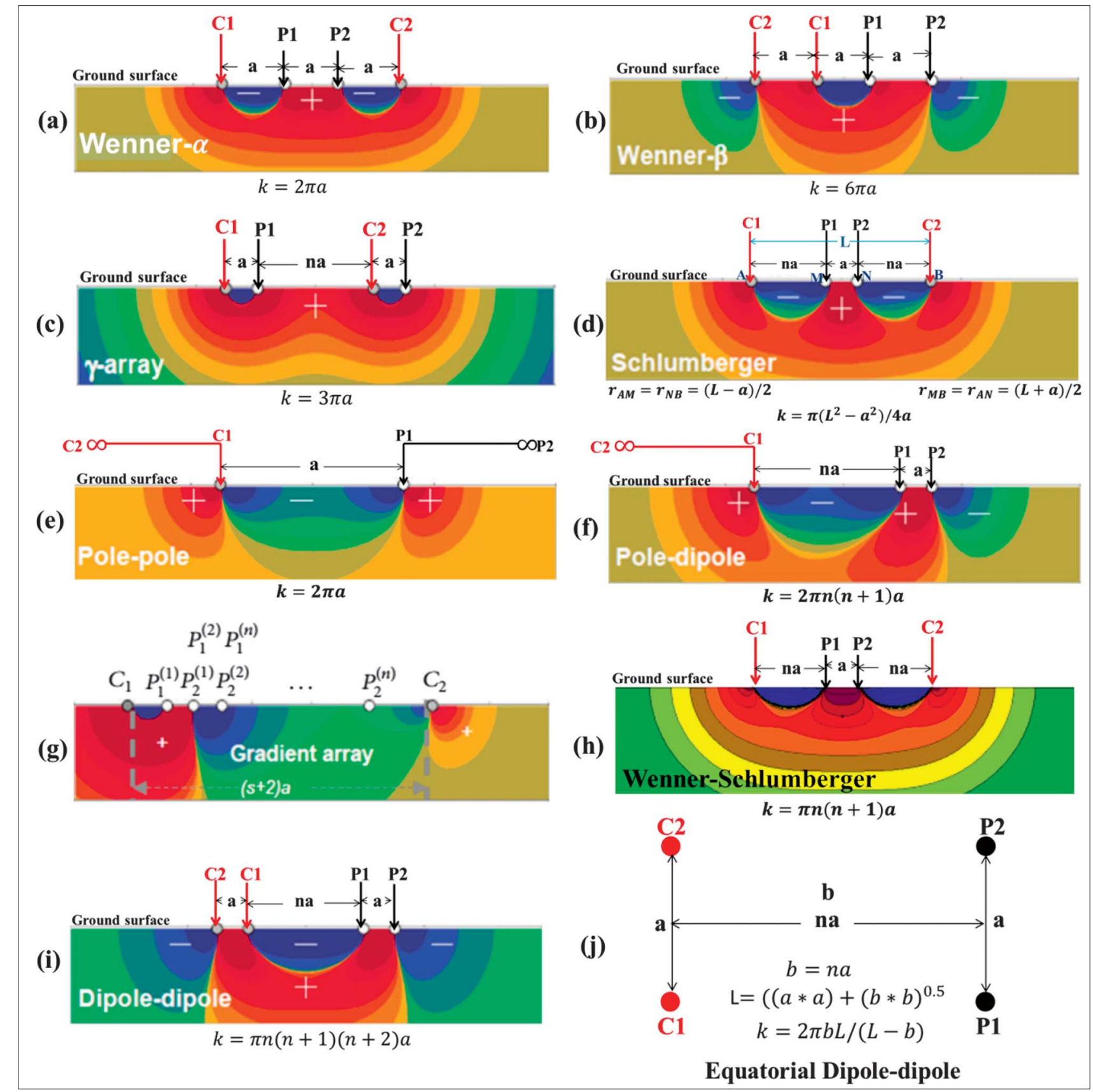

Figure 4: Array types with their respective configurations and geometric factors. $C(1,2)$ represents current electrode, $P(1,2)$ represents potential electrode, $n$ is an integer value for dipole separation factor, $a$ represents electrode spacing, $k$ is the geometric factor, and $\infty$ implies larger electrode separation of about 20 times the normal electrodes separation $a$. The background shows the sensitivity pattern of the configuration, in the gradient array case for the first potential electrode pair $(n-f a c t o r=1)$ (modified after Loke, 2002; Dahlin and Zhou, 2004).

tion between $P 1$ and $P 2$ electrodes resulting in a poor subsurface inversion model that smeared subsurface structures. Therefore, the array is mainly used in surveys of relatively small electrode spacing (less than $10 \mathrm{~m}$ ) (Loke, 2002).

iv. The pole-dipole array has a stronger signal strength compared with the dipole-dipole array, but lower than the Wenner and Wenner-Schlumberger arrays. Pole-dipole array electrodes are configured as $C 1 P 1 P 2$ but $C 2$ is at a sufficiently large distance than the normal electrodes separation (see Figure 4f). It is less sensitive to telluric noise than the pole-pole array because P1 P2 electrodes are within the survey profile. However, pole-dipole pseudo-section produces asymmetrical apparent resistivity anomalies over symmetrical structures because of the asymmetric electrodes arrangement; this is more difficult to interpret than the pseudo-sections of symmetrical arrays. Hence, measurements must be repeated 
with the electrodes reversed to annul this effect (Loke, 2002).

v. The Wenner-Schlumberger array (see Figure 4h) is a hybrid between Wenner-alpha $(\alpha)$ and Schlumberger arrays (Pazdirck and Blaha, 1996) but with a larger median depth of investigation than the Wenner array with the same distance between $C 1$ and $C 2$. This array is moderately sensitive to both horizontal and vertical structures, hence it may be considered for deriving a high resolution profile in areas where both geological structures are to be mapped. The Wenner-Schlumberger array has smaller signal strength and slightly wider horizontal data coverage than the Wenner array but has a higher signal strength and narrower horizontal data coverage than the dipole-dipole array (Loke, 2002).

vi. The dipole-dipole array is frequently used in resistivity and IP surveys because of its low EM coupling effect and can also be effectively used for depth sounding (Loke, 2002). The dipole-dipole array has two configurations - normal dipole-dipole (see Figure 4i) and equatorial dipoledipole (see Figure $\mathbf{4 j}$ ). The normal dipole-dipole has C2 C1 P1 P2 configuration while equatorial dipole-dipole has a similar configuration but in different directions. Due to its high sensitivity to horizontal variation and resistivity changes between the electrodes in each dipole pair, the array is highly suitable for mapping vertical structures like igneous dykes and cavities, but less for identifying horizontal structures like sills and sedimentary layers (Merritt, 2014).

\section{Electrical resistivity tomography}

Electrical resistivity tomography is a non-invasive survey technique recently developed for imaging subsurface features from electrical resistivity measurements made at the earth's surface, in cross-holes (boreholes), or underwater. ERT uses four electrodes for subsurface imaging in order to minimise the effect of contact resistance (Daily et al., 2000). The technique works by injecting an electrical current (artificial) into the subsurface and measuring the resulting potential difference at the surface along a series of constant traverse separation with increasing electrode spacing. Since increasing separation leads to greater depth penetration, the measured apparent resistivity is used to produce a pseudo-section displaying the variations of resistivities both laterally and vertically (Griffiths and Barker, 1993; Reynolds, 2007, 2011; Merritt, 2014).

The automated multi-electrode systems used for ERT have several desired advantages over conventional resistivity instruments. The systems speedup the data acquisition process by reducing the required time and laborious efforts of manually switching electrodes, improve the quality and resolution of large data sets (Tsourlos, 1995; Stummer and Maurer, 2001). These advancements have been useful in terms of reducing cost of deriving intrinsic subsurface information on a wider scale. The derived information is very useful to civil engineers, miners, structural geologists and hydrogeologists, among others instead of relying only on the results of single position methods such as coring, trenching and drilling. The resolution of electrical imaging rapidly declines with distance from the electrodes. However, the use of cross-hole survey by positioning electrodes closer to the area of interest, and the use of other available data from geotechnical survey, borehole log, etc can constrain the inversion model to reduce this limitation (Loke et al., 2013).

ERT has been extensively used in geotechnical, engineering and environmental (Grellier et al., 2008; Maslakowski et al., 2014), agricultural (Petersen and al Hagry, 2009), archaeological (Xu and Noel, 1991), soil water content (Cosentini et al., 2011), saturation (Abu-Hassanein et al., 1996), compaction (Seladji et al., 2010), pollution (Godio and Naldi, 2003), mineral exploration (Bauman, 2005; Legault et al., 2008), structures from millimetre scale to kilometres (Storz et al., 2000; Tabbagh et al., 2000; Lebourg et al., 2005; Linderholm et al., 2008), in cross boreholes (Chambers et al., 2003; Daily and Owen, 1991) investigations, etc. Besides, ERT has been adopted as a new technology for long-term embankment monitoring systems through time-lapse and real-time measurements (Barker and Moore, 1998; Gunn et al., 2010; Chambers et al., 2011a, b; Gunn et al., 2014; Merritt, 2014). Also, resolving complex geological problems, such as hidden underground structures identification or studying the spatiotemporal evolution of groundwater flow relative to landslide phenomena accurately has become easier through its innovative and robust inversion techniques (Dahlin and Zhou, 2006; Loke and Barker, 1996).

\section{1. $2 D$ and ${ }_{3} D$ roll-along techniques in ERT surveys}

The roll-along technique has been effectively used for the extension of a survey line with traverse positions that cannot be covered by normal take-outs cable length (see Figure 5). Two to four multi-core cable reels (see Figures 5a and b) may be used together in a given survey depending on the acquisition system, electrode configuration, dimension and geometry of the area to be investigated. The roll-along technique has been found useful for a variety of applications and offer better resolution even with its wider area coverage. This is possible because the acquisition system automatically transmits the required amount of current for increasing number of take-outs with respect to the depth of a probe.

There are several arrays/protocols in use for ERT surveys with/without the roll-along techniques. 


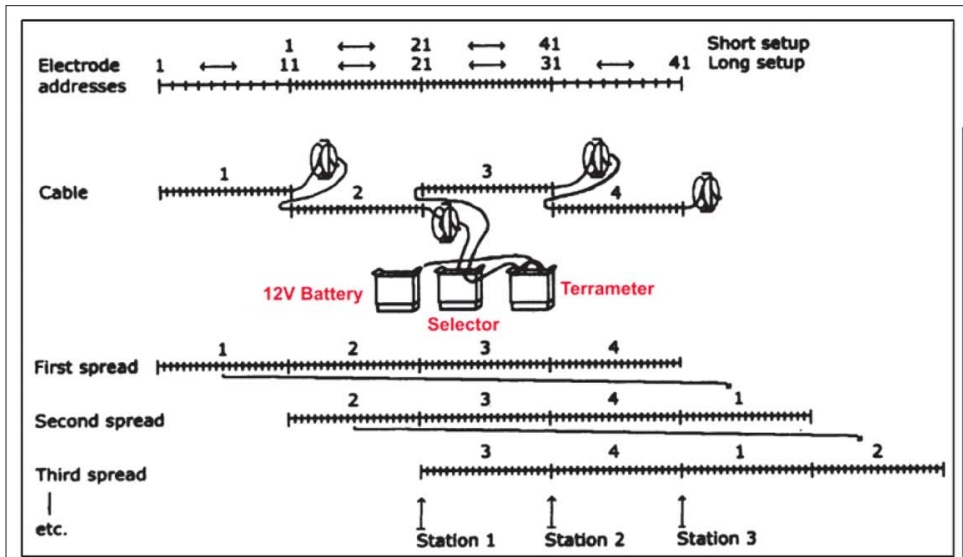

(a)

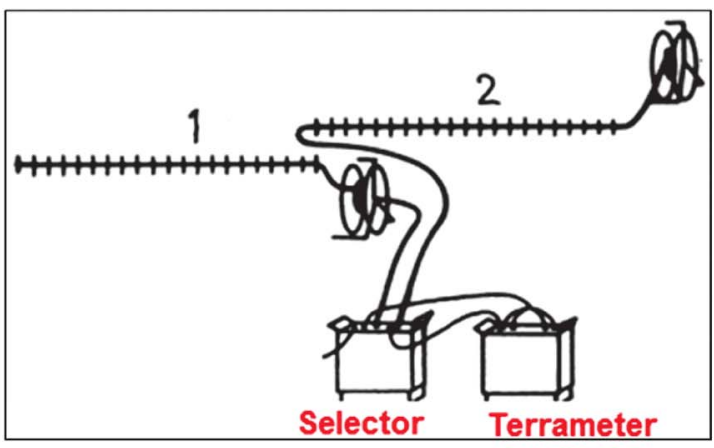

(b)

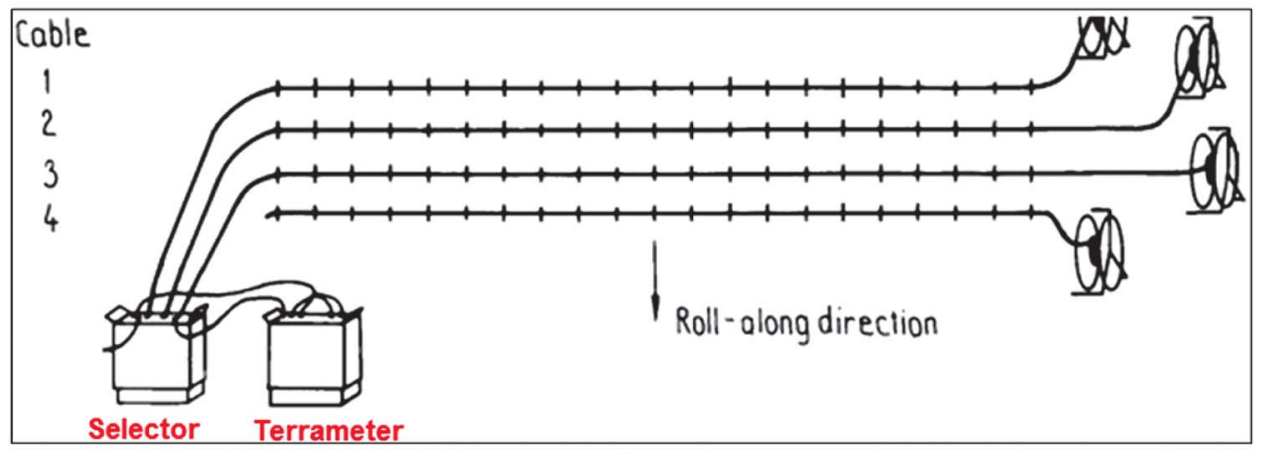

(c)

Figure 5: A typical system layout for roll-along technique; (a) using four electrode cables,

(b) using two electrode cables and, (c) for 3D survey (modified after ABEM, 2009).

For example, the Lund Resistivity Imaging System makes use of some of these protocols: WEN32SX (1-Channel multiple array with 2 Electrode cables), GRAD4L8 + GRAD4S8 (4-Channel multiple array with 4 Electrode cables), GRAD1L7 + GRAD1S7 (1-Channel multiple array with 4 Electrode cables), DIPDIP4L + DIPDIP4S (4-Channel Dipole-Dipole array with 4 Electrode cables), POLDIP4L + POLDIP4S (4-Channel Pole-Dipole array with 4 Electrode cables), POL8X8 (Pole-Pole in 8X8 Square grid), etc. The $L$ and $S$ in the protocol mean Long and Short layout respectively. Note that it is important to select the protocol files in the correct order, starting with the protocol for the long layout before selecting the protocol for the short layout. The long layout protocol takes account of a dense near-surface cover and a slightly sparser measurement pattern at long electrode spacing, while the short layout is designed to supplement the long layout data to enhance near surface resolution (ABEM, 2009).

Most of the commercial 3D ERT data acquisition surveys probably use a grid of at least 16 by 16 , or 10 by 10 , or 10 by 5 (see Figure 7 for other examples). The grid of at least 16 by 16 requires 256 electrodes which are more than what is available on many multi-electrode resistivity systems for covering a reasonably large area. To solve issue of this kind, there is need for extending the roll-along technique used for $2 \mathrm{D}$ surveys to $3 \mathrm{D}$ surveys see (Figure 5c) (Dahlin and Bernstone, 1997; Loke et al., 2013).

\subsection{Electrical resistivity tomography field survey design and data acquisition}

Some of the resistivity acquisition systems in use are: LUND Resistivity Imaging System (ABEM), MacOhm 21 (DAP-21) Imaging System (OYO) and Sting/Swift, among others. The whole field data acquisition procedure is controlled through the computerised in-built system in any of these sophisticated acquisition systems.

The imaging acquisition systems work as both transmitter and receiver and consist of: Terrameter (e.g. ABEM Terrameter SAS 1000/4000); electrode selector also known as the switching unit (e.g. ES 464, ES 10-64C, etc.); multi-core cables usually with a quantity of cable joints (take-outs); power source, and stainless steel electrodes to minimise the effects of electrode polarisation.

ERT imaging is performed by matching the measured apparent resistivity pseudo-section to a computed pseudo-section that is obtained by solving for a given earth resistivity structure $\rho(r)$ using the scaled-Laplace equation (Everett, 2013):

$$
\nabla \cdot([1 / \rho] \nabla \varphi)=0
$$




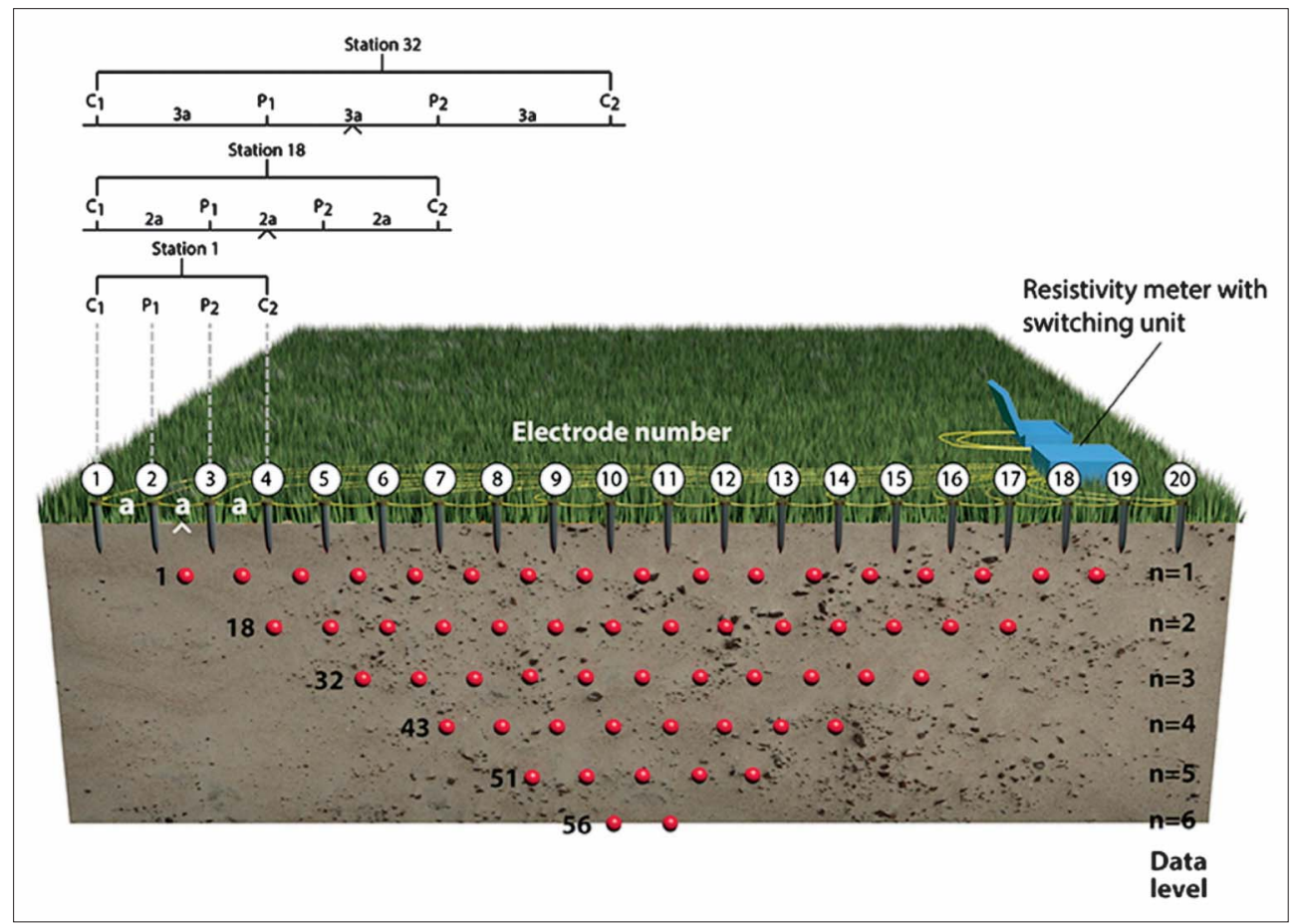

Figure 6: Schematic diagram of a multi-electrode system, and a possible sequence of measurements to create a $2 \mathrm{D}$ pseudo-section (Loke et al., 2013).

The electric potential distribution $\varphi(r)$ is evaluated at the locations of the potential electrodes and transformed into a computed apparent resistivity. The model is then adjusted, and the apparent resistivity re-computed, until it matches the measured apparent resistivity to within a pre-defined acceptable tolerance (Loke, 2002, 2004; Everett, 2013). ERT surveys can be performed in either $2 \mathrm{D}$ or $3 \mathrm{D}$ depending on the nature of investigation and parameter of interest to be determined in the subsurface.

2D ERT surveys are carried out using two or four sets of multi-core cable reels with a series of take-outs of equal intervals for grounded electrodes to be connected to them via cable jumpers. The length of the multi-core cable determines the length of the initial profile without roll-along. The acquisition setups for 2D ERT measurements (see Figure 6) are in stages after all take-outs have been connected to grounded electrodes. Firstly, the extended connector sockets from the reference electrode are connected to the switching unit. Thereafter, the switching unit is connected to the resistivity meter by a special cable. The resistivity meter is then connected to a power source, usually a car battery. The sequence of electrical measurements, array type and amount of current to be injected is determined by the resistivity meter while the switching unit controls which electrodes inject current and which electrodes measure the potential difference. The technique requires collection of data at several multiples of $a$ (commonly up to $16 a$ ) to provide information at a range of depths, termed $n$ levels. Each $n$ level effectively corresponds to a constant separation traverse at a fixed multiple of $a$. The acquisition system can be set to run automatically through the required number of levels, and also perform noise checking and re-acquiring of bad data points. Reciprocal measurements are usually taken to ascertain data quality using a reciprocal error of $5 \%$ or $10 \%$ as an arbitrary cut-off between good and bad data. The resultant measured resistivity values are inverted using special software to produce an inverse model resistivity section (Dahlin, 1996; Reynolds, 2011).

In 3D surveys, the pole-pole, pole-dipole and dipoledipole arrays are often used because they have better resolution at the edges of the survey grid than other arrays (Loke 2002). The field layout is usually arranged in a square grid with equal electrode spacing along $x$ and $y$ directions (see Figure 7). However, a rectangular grid with different numbers of electrodes and spacing may be used for elongated bodies. According to Loke (2002), 3D surveys are performed in a number of ways, which are: category one, two, three and four. In category one, measurements are taken along possible directions with electrodes arranged in a rectangular grid. Category two has all electrodes arranged in a rectangular grid and measurements are taken along all the grid lines, but limited measurements are made at an angle to the grid lines. Category three is used when multi-electrode system has limited nodes to cover an entire survey area, but measurements are only in two directions along grid lines. In the category four, measurements are taken only along a series of parallel 2D survey lines while the $3 \mathrm{D}$ subsurface resistivity model is produced by combining and inverting all the parallel $2 \mathrm{D}$ lines together. However, the distance between parallel $2 \mathrm{D}$ resistivity lines should be 


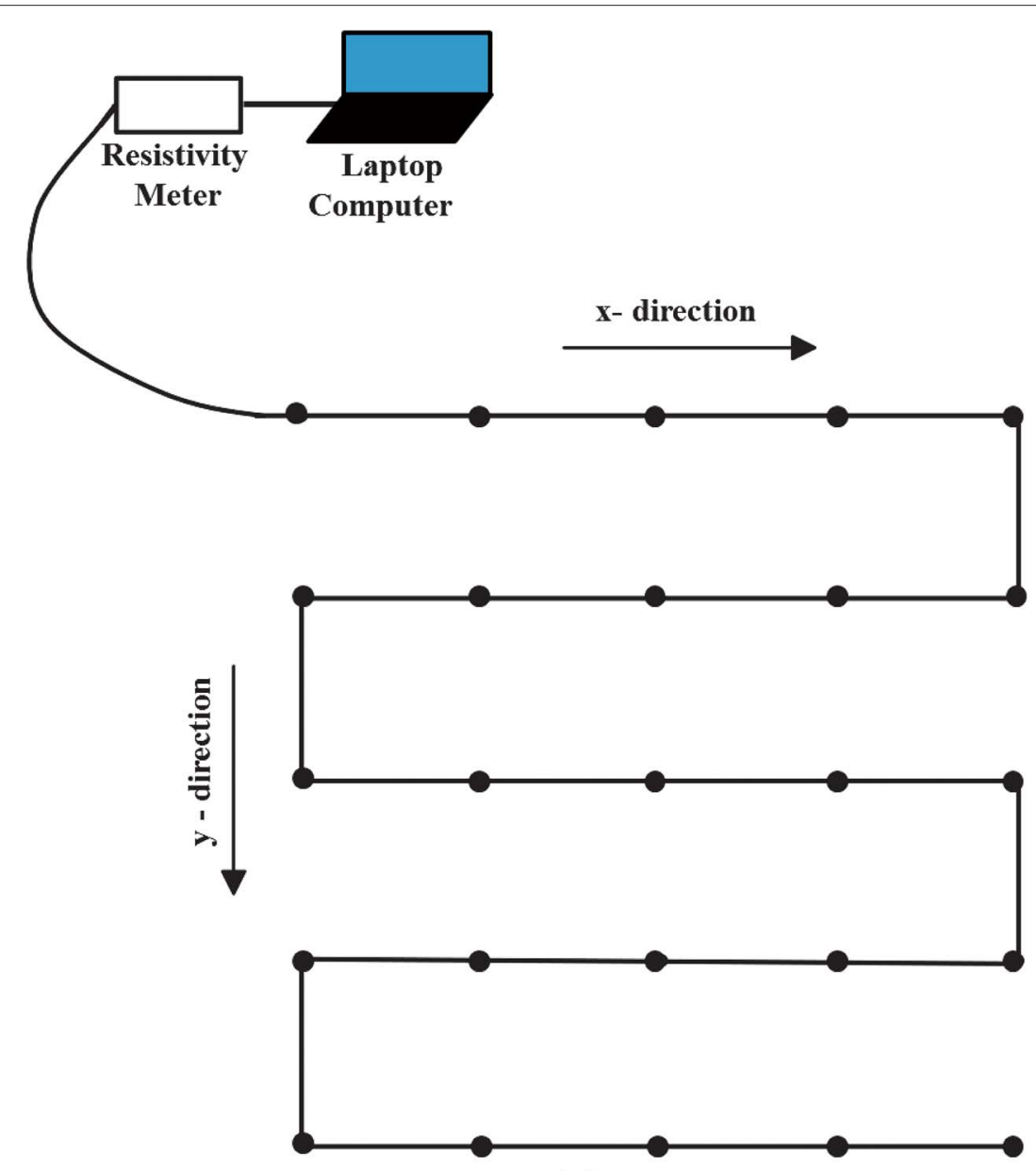

Electrode

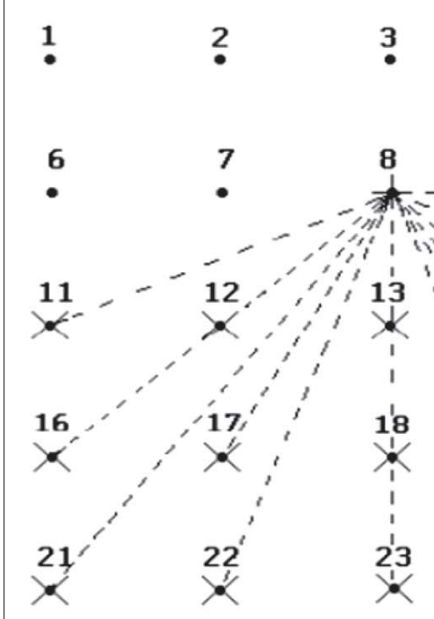

(b)

(a)
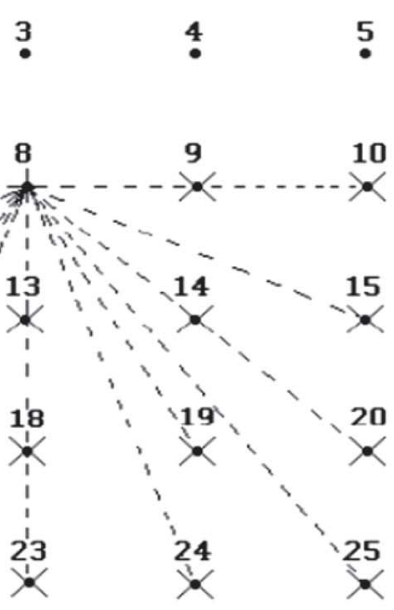

$\uparrow$ current

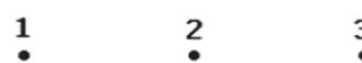

$3 \quad 4$

$\mathbf{5}$

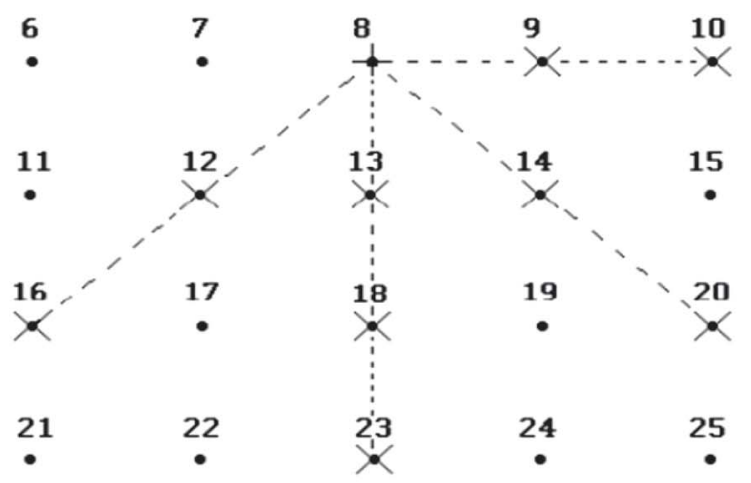

potential

electrode

(c)

Figure 7: (a) A typical 3D survey layout for arrangement of electrodes. Two possible measurement layouts for a $3 \mathrm{D}$ survey are: (b) a survey for measuring complete data set and, (c) a cross-diagonal survey (modified after Loke and Barker, 1996; Loke 20o2).

equal to the electrode spacing in order to achieve this. For quality data coverage, field measurements should be taken in either category one or two for angular data to be included in the acquired data because such information would not be captured in measurements taken in either category three or four. 


\subsubsection{Cross-hole (borehole) ERT survey}

The major limitation of ERT survey conducted at the earth's surface has to do with the resolution of resistivity images with depth because the electrodes do not have direct contact with subsurface layers. Therefore, crosshole ERT survey is mainly used to improve subsurface image resolution. Cross-hole ERT employs various quadripole combinations of current and potential electrodes, either in the same hole, between the hole and the surface or between pairs of holes (see Figure 8) (Daily et al., 2000; Loke et al., 2013). The separation of the holes should not be more than about 0.75 times the borehole array length in order to achieve acceptable image resolution (LaBrecque et al., 1996). Boreholes layout can be regular or irregular (Wilkinson et al., 2006; Tso-

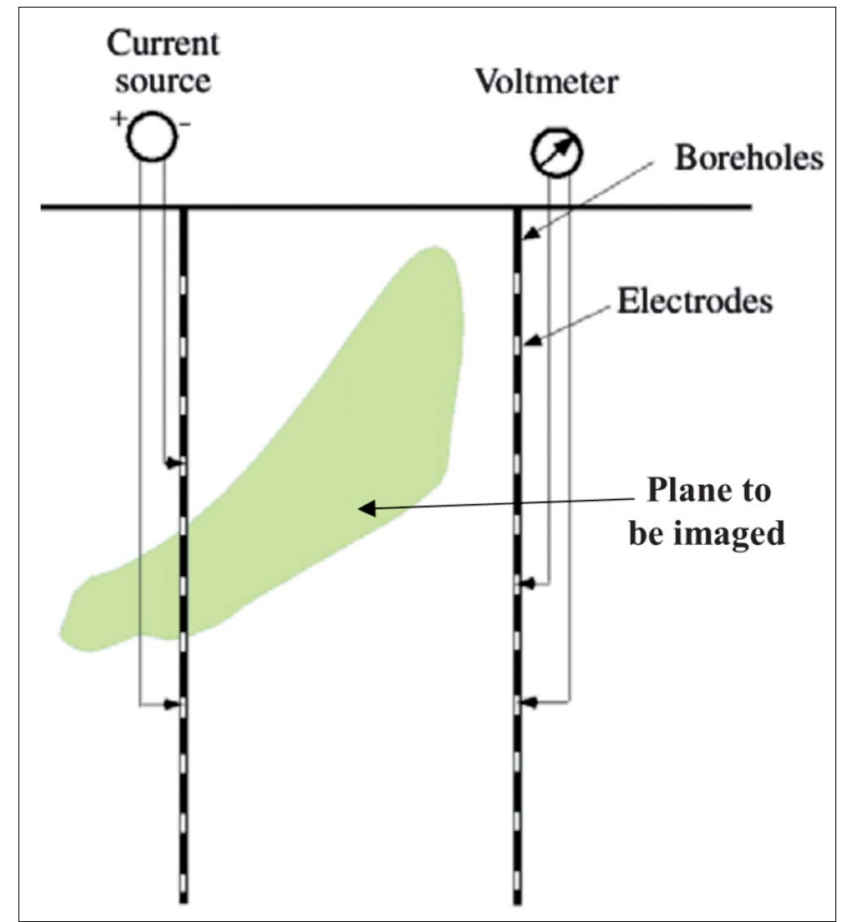

Figure 8: Schematic of ERT measurement in cross-borehole (modified after Daily et al., 20oo). kas et al., 2011) depending on the area of investigation and ground conditions. Determination of accurate positions for borehole electrodes is more difficult than surface electrodes; therefore the effects of random and systematic offsets in electrode positions and deviations of the boreholes from their assumed locations and direction must be put into consideration (Loke et al., 2013). Other limitations of cross-hole ERT survey are given in the works of Singer and Strack (1998); Denis et al. (2002); Nimmer et al. (2008), and Loke et al. (2013).

\subsubsection{Mobile - land and underwater ERT survey}

The mobile ERT imaging syatem is used on land (e.g. Aarhus Pulled Array System) and underwater (Sorensen, 1996; Bernstone and Dahlin,1999; Loke 2002). The underwater mobile ERT imaging technique can be conducted at the water surface with floating electrodes or submerged at the floor to investigate the subsurface condition beneath the river/stream/lake/sea floor through continuous resistivity profiling. The method may be more beneficial to use fixed submerged arrays in extremely shallow streams instead of continuous resistivity profiling to prevent cable damage (Loke et al., 2013). However, floating electrodes are best recommended when a water column is no greater than $25 \%$ of the total depth of investigation (Loke and Lane, 2004). Figure 9 shows one of the possible arrangements of an underwater mobile imaging systems that employed the WennerSchlumberger configuration using a cable with a number of nodes being pulled along the river/lake/sea bottom by a boat. The nodes consist of two fixed current electrodes (C1 and $C 2$ ) while the rest are used as potential electrodes $(P)$ to measure the potential at different spacing. This type of imaging system can be used with other array like the gradient array.

\subsection{Electrical resistivity tomography inversion}

ERT inversion program is a computer program that automatically generates $2 \mathrm{D}$ resistivity model of the subsurface for a data set from resistivity imaging surveys of

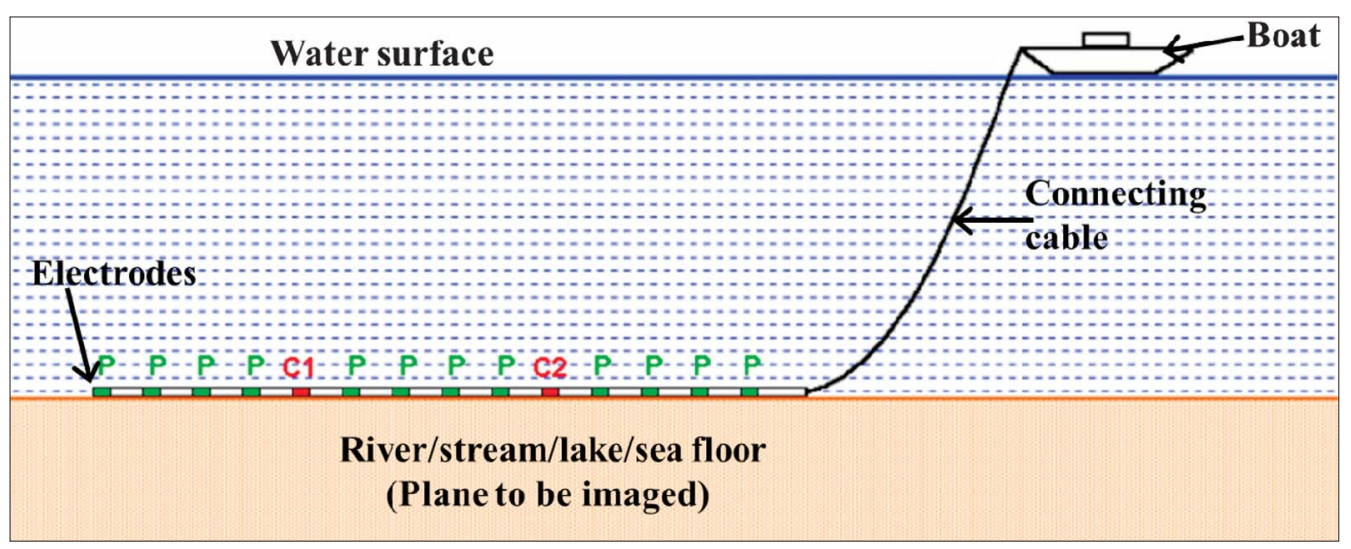

Figure 9: Schematic diagram of a submerged mobile underwater survey system (modified after Loke, 2002). 
conventional or non-conventional arrays with an almost unlimited number of possible electrode configurations of uniform or non-uniform electrode spacing, and for underwater and cross-borehole surveys (Griffiths and Barker, 1993; Dahlin, 1996). The inversion routine used by the program is based on the smoothness-constrained least-squares method that supports both the quasi-Newton and Gauss-Newton least-square optimisation methods. Gauss-Newton method gives slightly better results for a model with large resistivity contrasts greater than 10:1 that can have an erratic resistivity distribution with spurious high or low resistivity zones, but slower than the quasi-Newton method (Loke and Barker, 1996; Loke and Dahlin, 2002; Loke, 2002). The smoothness-constrained least-squares method is based on Equation 14:

$$
\left(J^{T} J+u F\right) d=J^{T} g
$$

where $F=f_{x} f_{x}^{T}+f_{z} f_{z}^{T}$

$f_{x}=$ horizontal flatness filter,

$f_{Z}=$ vertical flatness filter,

$J=$ matrix of partial derivatives,

$u=$ damping factor,

$d=$ model perturbation vector,

$g=$ discrepancy vector

This mathematical inverse problem determines the subsurface distribution of resistivity from measurements of apparent resistivity data sets to produce a subsurface inverted model that agrees mostly with the field apparent resistivity measurements based on predefined numbers of iterations for convergence. The subsurface is divided into a lot of rectangular cells during modelling, the resistivities of the cells are determined by the inversion algorithm, but might not always give the ideal resistivities because the cell-based inversion may employ a lot of assumptions to model complex geological structures (Loke, 2002).

A summary of the stages involved in inversion processes for data reductions and for generating the final inversion model resistivity section is given below and in Figures 10a and b:

i. Files in the Terrameter are saved in binary formats. This format is not compatible with the inversion software program so it has to be converted to a software readable file format. For example, using the conversion subroutine in SAS 4000 Utilities or Erigraph to convert from.s $4 k$ to.dat format.

ii. Data editing is performed to remove bad data points that have resistivity values which are clearly wrong due to the failure of the relays at one of the electrodes, poor electrode ground contact due to dry soil, or shorting across the cables due to wet ground conditions. The bad data points have apparent resistivity values that are obviously too large or too small compared to the neighbouring data points (Loke, 2004). The val- ues are dropped so that they do not influence the model obtained.

iii. Reciprocal measurement for data assessment and editing may be employed to determine the percentage error resulting from interchanging of current and potential electrodes in contrast to the normal array of 2-current and 2-potential electrodes (Zhou and Dahlin, 2003; Wilkinson et al., 2012).

iv. Splicing is adopted for too large data sets in order to choose a section from the segmented data sets to be processed at a single time (Loke, 2004).

v. Forward modelling subroutine - Finite-difference and finite-element methods. 2D/3D model apparent resistivity and Jacobian matrix values are calculated through a mathematical link between the model parameter and the response model provided by finite-difference (Dey and Morrison, 1979a, b; Loke, 1994) or finite-element methods (Silvester and Ferrari, 1990). Finite-difference method is usually considered faster for data sets without topography while the finite-element method is used for data sets with topography. Using a finite-element of 4 nodes gives a more accurately calculated apparent resistivity values than 2 nodes, particularly for large resistivity contrasts. When $\mathrm{L}_{1}$-norm (robust inversion) is incorporated with it, more stable results may be achieved (Zhou and Dahlin, 2003; Dahlin and Zhou, 2004).

vi. The ratio of vertical flatness filter $\left(f_{z}\right)$ to horizontal flatness filter $\left(f_{r}\right)$ is used for smoothing and reducing elongated vertical and horizontal anomalies in the pseudo-section. Higher vertical to horizontal flatness ratio values for elongated vertical anomalies and lower ratio values for elongated horizontal anomalies are considered to produce a better pseudo-section (Loke, 2004).

vii. Models with very noisy and less noisy data sets, as well as unnatural oscillations in the lower section are taken care of during inversion by adjusting the damping factor $(u)$ value. Relatively large damping factor is used for very noisy data sets and unnatural oscillations while a smaller damping factor is used for less noisy data sets to generate a better inversion model. However, a minimum limit of about one-fifth of the initial damping factor for damping factor value may be used to stabilise the inversion process (deGroot-Hedlin and Constable, 1990; Loke, 2004).

viii. The inversion/model refinement allows the user to choose a model with cell width with normal electrode spacing or cell width with half electrode spacing for optimum result. Cell width with half electrode spacing gives better resolution and smoothens the model than cell width of normal electrode spacing because the program 


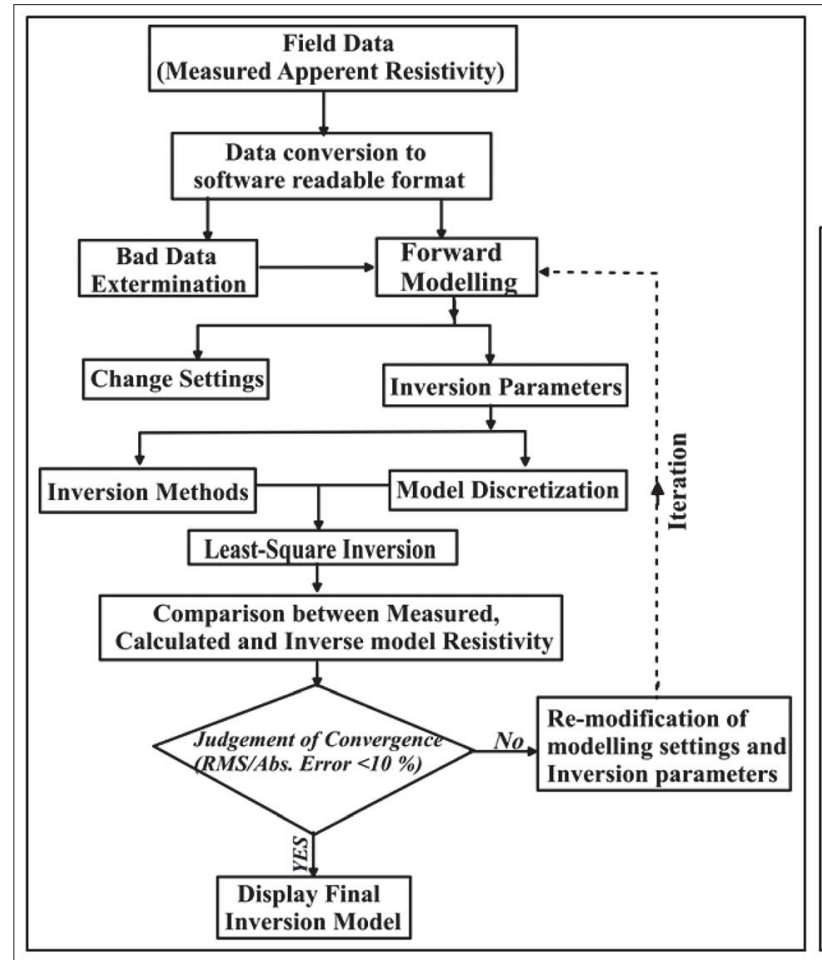

(a)

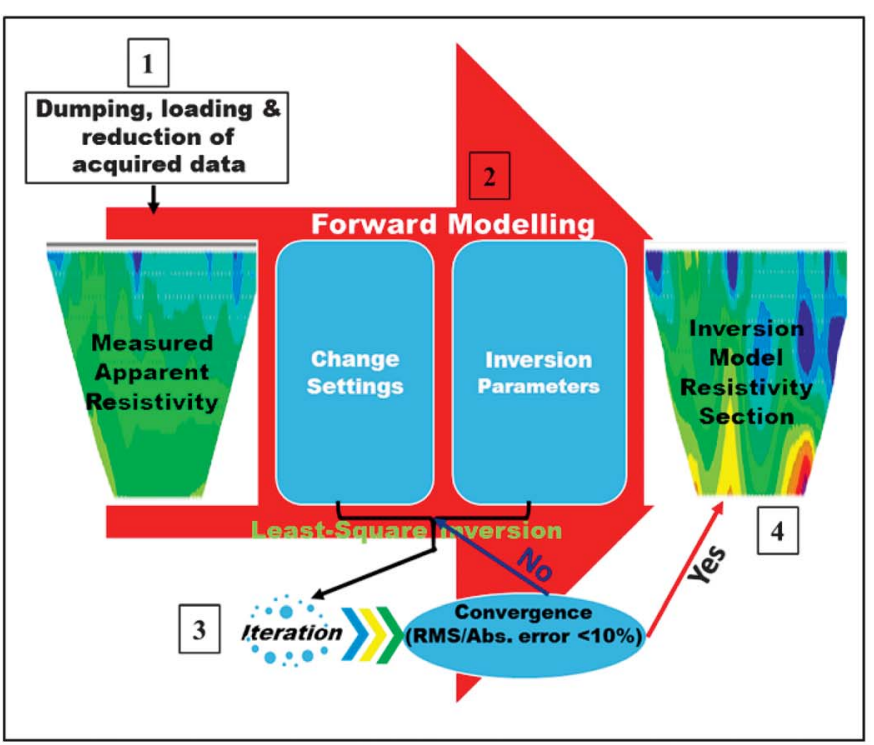

(b)

Figure 10: (a) ERT data processing and inversion flow chart; (b) Simplified ERT data inversion flow diagram showing different processing stages (1 - 4) (modified after Akingboye, 2018).

attempts to reduce misfit of failure from the near surface variations that could lead to distortions in the lower section of the model (Loke, 2004).

ix. For achieving root mean square (RMS) or absolute (Abs.) error less than $10 \%$, the iteration subroutine is usually set to 5 iterations for convergence, but can be continued to about 10 iterations in case model RMS/Abs error is higher than the required convergence limit. According to Loke (2004), model with the lowest RMS error is not always the best model particularly for very noisy data sets.

\section{Conventional seismic refraction and electrical resistivity methods versus SRT and ERT Techniques}

Why use the tomography techniques (SRT and ERT) over their conventional methods for subsurface investigations? The answers to the question are not farfetched. Having discussed the conventional seismic refraction and electrical resistivity methods and their tomographic techniques, their differences are discussed in the sections below:

\subsection{Conventional seismic refraction versus seismic refraction tomography}

i. Conventional seismic refraction and SRT employ the same field data acquisition equipment but field acquisition and inversion techniques and models are different.

ii. In the field procedure, SRT employs more survey lines, shotpoints and receivers for dense and high resolution data than conventional seismic refraction survey.

iii. SRT can be employed for different applications on a large scale and to resolve complex subsurface geological conditions, as well as to fit more flexible velocity models where the conventional refraction method fails.

iv. Conventional seismic refraction data processing is deficient in showing the true strength of subsurface earth materials because it uses overgeneralised geometry for breaking model into continuous layers of constant velocity, whereas SRT does not require that the model be broken into constant velocity continuous layers but uses higher number of small constant velocity grid cells or nodes (Zhang and Toksoz, 1998).

v. Both methods measure traveltimes of seismic waves and pick the first arrivals (compressional or P-waves) of the traces, however, SRT inversion software uses more complex mathematical algorithms to produce more detailed and comprehensive velocity models that can sufficiently resolve subsurface velocity gradients and lateral velocity changes.

vi. SRT tomogram/inversion model can resolve geophysical conditions such as mapping discrete 
bodies like boulders, cavities, etc, as well as complex subsurface geology that may be difficult to achieve with the conventional refraction method.

vii. However, conventional seismic refraction is more cost-effective for a lot of simple problems, especially depth to bedrock, mapping of undulating interfaces, etc because of the simple field technique.

\subsection{Conventional electrical methods versus electrical resistivity tomography}

i. In the field procedure, once the electrodes, cables and connectors are set up, ERT behaves like a robot by selecting the required four electrodes automatically, thus saves time unlike the non-ERT techniques that require the moving of electrodes manually.

ii. During field data acquisition, ERT measurement is automated but the conventional method is done manually by moving the electrodes along the traverse. This improvement in ERT makes it possible for data to be collected by a single person after traverse has been laid unlike the conventional electrical resistivity that requires two or more persons for such field activity, therefore, data acquisition becomes more cost-effective than the non-ERT techniques. Besides, the precision in data collection and data processing are higher for ERT than conventional electrical methods that are often prone to errors due to laborious field survey and human fatigue.

iii. ERT covers large area up to several hundreds of metres even kilometres using its roll-along techniques within a short time but the conventional electrical resistivity takes longer time to run over such distances because electrodes are manually moved.

iv. The data inversion techniques are also different for both methods. ERT uses more complex mathematical algorithms to fit and generate its subsurface model, thus this makes the model more robust and of higher resolution than those produced by the non-ERT methods.

v. ERT tomogram/inversion model can resolve geophysical conditions such as mapping discrete bodies like boulders, cavities and pollution plume that may be difficult to achieve with the conventional electrical methods (Loke, 2002).

vi. A depth probe using ERT method is more reliable than the case with non-ERT methods.

\section{Conclusions}

In the last two decades, the advancement in imaging techniques through fast field data acquisition systems and designs, as well as development of complex inver- sion software used for SRT and ERT have greatly improved the quality of acquired data for resolving complex subsurface features. The field data acquisition technique of SRT requires more shotpoints and geophone receivers than its conventional method while the ERT employs automated multi-electrode Resistivity Imaging System connected by multicore cables to several grounded electrodes. The field surveys can either be $2 \mathrm{D}$ or $3 \mathrm{D}$ depending on the geometry and complexity of the area to be investigated. The 3D surveys provide more valuable details of the subsurface characteristics and conditions for complex geological areas where 2D models suffer from limitation such as artifacts. The resolution of acquired data by the SRT technique may generally be reduced by a decrease in the amount of propagating seismic energies and larger distance away from geophones while that of ERT may be due to decrease in amount of penetrating current with respect to depth of probing and a larger distance from the potential electrodes. However, an increase in the amount of energy sources and shotpoints for SRT and the use of electrodes that are positioned closer to the zone of interest in cross-hole for ERT can reduce these limitations.

The inversion techniques of SRT and ERT seek to produce the subsurface models that mostly agree with the calculated field models for the velocities and resistivities of earth's subsurface features respectively. The generated 2D and 3D models clearly evince the subsurface variations both laterally and vertically with better resolution that efficiently annul inaccurate subsurface boundary demarcation and structural mapping that may be difficult for their conventional methods.

Based on the efficiency of field techniques, larger area coverage, faster and higher subsurface resolution inversion models of these state-of-the-art techniques over their mostly used conventional methods in geophysical investigations have greatly proffer solutions in solving vital problems related to hydrogeology, engineering, environmental, mineral exploration etc, especially in areas of complex geology. SRT and ERT techniques can work efficiently in both basement and sedimentary terrains to investigate variations in earth's subsurface features. Their models can be used to infer intrinsic subsurface characteristics that may accurately resolve complex subsurface geological conditions such as cavities, boulders, pollution plume etc. In regions with very thick overburden covers, SRT should be integrated with ERT technique for better results because of its greater depth probing capacity.

\section{References}

\section{Papers:}

Abu-Hassanein, Z., Benson, C. and Blotz, L. (1996): Electrical resistivity of compacted clays. Journal of Geotechnical Engineering, 122, 97-406. 
Arjwech, R. and Everett, M.E. (2015): Application of 2D electrical resistivity tomography to engineering projects: Three case studies. Songklanakarin Journal of Science and Technology, 37, 675-682.

Ayolabi, E.A., Folorunso, A.F, and Idem, S.S. (2012): Application of electrical resistivity tomography in mapping subsurface hydrocarbon contamination. Earth Science Research, 2, 93-103.

Azwin, I.N., Saad, R. and Nordiana, M. (2013): Applying the Seismic Refraction Tomography for Site Characterisation. APCBEE Procedia (Elsevier), 5, 227-231.

Barker, R. and Moore, J. (1998): The application of time lapse electrical tomography in groundwater studies. Leading Edge, 17, 1454-1458.

Bernard, J. (2003): Short notes on the principles of geophysical methods for groundwater investigations. 1-8.

Bernstone, C. and Dahlin, T. (1999): Assessment of two automated electrical resistivity data acquisition systems for landfill location surveys: Two case histories. Journal of Environmental and Engineering Geophysics, 4, 113-122.

Berry, A.A. (2013): High Resolution in Seismic Refraction Tomography for Environmental Study. International Journal of Geosciences, 4, 792-796, http://dx.doi.org/10.4236/ ijg.2013.44073

Bery, A.A. and Saad, R. (2012a): Correlation of Seismic PWave Velocities with Engineering Parameters (N Value and Rock Quality) for Tropical Environmental Study. International Journal of Geosciences, 3, 749-757, doi: 10.4236/ijg.2012.34075

Bery, A.A. and Saad, R. (2012b): Analysis and Imaging Subsurface Structure via Engineering Characterizations and Integrated Geophysical Tomography Modelling Methods. International Journal of Geosciences, 3, 93-104, doi: 10.4236/ijg.2012.31011

Cardarelli, E. and de Nardis, R. (2001): Seismic refraction, isotropic and anisotropic seismic tomography on an ancient monument (Antonino and Faustina temple AD141). Geophysical Prospecting, 49, 228-41.

Chambers, J.E., Loke, M.H., Ogilvy, R.D. and Meldrum, P.I. (2003): Non-invasive monitoring of DNAPL migration through a saturated porous medium using electrical impedance tomography. Journal of Contaminant Hydrology, 68, $1-22$.

Chambers, J.E., Wilkinson, P.B., Kuras, O., Ford, J. R., Gunn, D.A., Meldrum, P.I., Pennington, C.V.L., Weller, A.L., Hobbs, P.R.N. and Ogilvy, R.D. (2011b): Three dimensional geophysical anatomy of an active landslide in Lias Group mudrocks, Cleveland Basin, UK. Geomorphology, $125,472-484$.

Colangelo, G., Lapenna, V., Loperte, A., Perrone, A. and Telesca, L. (2008): 2D electrical resistivity tomography for investigating recent activation landslides in Basilicata Region (Southern Italy). Annals of Geophysics, 51, 275-285.

Dahlin, T and Bernstone, C. (1997): A roll-along technique for 3D resistivity data acquisition with multi-electrode arrays/ Proceedings of Symposium on the Application of Geophysics to Engineering and Environmental Problems (SAGEEP). Reno, Nevada. March 23-26, 2, 927-935.
Dahlin, T. (1996): 2D resistivity surveying for environmental and engineering applications. First Break, 14, 275-284.

Dahlin, T. and Zhou, B. (2004): A numerical comparison of 2D resistivity imaging using 10 electrode arrays. Geophysical Prospecting, 52, 379-398.

Dahlin, T. and Zhou, B. (2006): Multiple-gradient array measurements for multichannel 2D resistivity imaging. Near Surface Geophysics, 113-123.

Daily, W. and Owen, E. (1991): Cross-borehole resistivity tomography. Geophysics, 56, 1228-1235

Daily, W., Ramirez, A., Binley, A. and LaBrecque, D. (2000): Electrical Resistance Tomography - Theory and Practice. The Leading Edge, 573-598, doi: 10.2172/15010154

deGroot-Hedlin, C. and Constable, S.C. (1990): Occam's inversion to generate smooth two-dimensional models from magnetotelluric data. Geophysics, 55, 1613-1624.

Denis, A., Marache, A., Obellianne, T. and Breysse, D. (2002): Electrical resistivity borehole measurements: application to an urban tunnel site. Journal of Applied Geophysics, 50, 3, 319-331.

Dey, A. and Morrison, H.F. (1979a): Resistivity modelling for arbitrarily shaped two-dimensional structures. Geophysical Prospecting, 27, 1020-1036.

Dey, A. and Morrison, H.F. (1979b): Resistivity modelling for arbitrarily shaped three-dimensional structures. Geophysical, 44, 753-780.

Dutta, P.N. (1984): Seismic refraction method to study the foundation rock of a dam. Geophysical Prospecting, 32, 1103-1110.

Godio A. and Naldi, M. (2003): Two-dimensional electrical imaging for detection of hydrocarbon contaminants. NearSurface Geophysics, 13, 131-137.

Grellier, S., Guerin, R., Robain, H., Bobachev, A., Vermeersch, F. and Tabbagh, A. (2008): Monitoring of leachate recirculation in a bioreactor landfill by 2-D electrical resistivity imaging. Journal of Environmental and Engineering Geophysics, 13, 4, 351-359.

Griffiths, D.H. and Barker, R.D. (1993): Two-dimensional resistivity imaging and modelling in areas of complex geology. Journal of Applied Geophysics, 29, 211-226.

Griffiths, D.H. and Barker, R.D. (1994): Electrical imaging in archaeology. Journal of Archaeological Science, 21, 2, 153-158.

Griffiths, D.H., Turnbull, J. and Olayinka, A.I. (1990): Two dimensional resistivity mapping with a computer-controlled array. First Break, 8, 4, 121-129.

Gunn, D.A., Chambers, J.E., Uhlemann, S., Wilkinson, P.B., Meldrum, P.I., Dijkstra, T. A., Haslam, E., Kirkham, M., Wragg, J., Holyoake, S., Hughes, P.N., Hen-Jones, R. and Glendinning, S. (2014): Moisture monitoring in clay embankments using electrical resistivity tomography. Construction and Building Materials, 1-13.

Hayashi, K. and Takahashi, T. (2001): High Resolution Seismic Refraction Method Using Surface and Borehole Data for Site Characterization of Rocks. International Journal of Rock Mechanics and Mining Sciences, 38, 807-813.

Kim, J.H., Yi, M.J., Park, S.G. and Kim, J.G. (2009): 4D inversion of DC resistivity monitoring data acquired over a 
dynamically changing earth model. Journal of Applied Geophysics, 68, 522-532.

LaBrecque, D.J., Ramirez, A.L., Daily, W.D., Binley, A.M. and Schima, S.A. (1996): ERT monitoring of environmental remediation processes. Measurement Science and Technology, 7, 3, 375-385.

Lapenna, V., Lorenzo, P., Perrone, A., Piscitelli, S., Rizzo, E. and Sdao, F. (2005): Case history: 2D electrical resistivity imaging of some complex landslides in Lucanian Apennine (Southern Italy). Geophysics, 70, 3, 11-18.

Lebourg, T., Binet, S., Tric, E., Jomard, H., El Bedoui, S. (2005): Geophysical survey to estimate the 3D sliding surface and the 4D evolution of the water pressure on part of a deep seated landslide. Terra Nova, 17, 5, 399-406

Legault, J.M., Carriere, D. and Petrie, L. (2008): Synthetic model testing and distributed acquisition dc resistivity results over an unconformity uranium target from the Athabasca Basin, northern Saskatchewan. The Leading Edge, 27, 1, 46-51.

Linderholm, P., Marescot, L., Loke, M.H. and Renaud, P. (2008): Cell culture imaging using microimpedance tomography. IEEE Transactions on Biomedical Engineering, $55,1,138-146$.

Loke, M.H. and Barker, R.D. (1996): Rapid least-squares inversion of apparent resistivity pseudosections by a quasiNewton method. Geophysical Prospecting, 44, 131-152.

Loke, M.H. and Dahlin, T. (2002): A comparison of GaussNewton and quasi-Newton methods in resistivity imaging inversion. Journal of Applied Geophysics, 49, 149-162, doi: 10.1016/S0926-9851(01)00106-9

Loke, M.H. and Lane Jr., J.W. (2004): Inversion of data from electrical resistivity imaging surveys in water-covered areas. Exploration Geophysics, 35, 4, 266-271.

Loke, M.H., Chambers, J.E., Rucker, D.F., Kuras, O. and Wilkinson P.B. (2013): Recent developments in the directcurrent geoelectrical imaging method. Journal of Applied Geophysics, 195, 135-156.

Maslakowski, M., Kowalczyk, S., and Józefiak, K. (2014): Using electrical resistivity tomography (ERT) as a tool in Geotechnical investigation of the subsurface of a highway. Studia Quaternaria, 31(2), 83-89, doi: 102478/squa2014-0008

Moser, T.J. (1991): Shortest Path Calculation of Seismic Rays. Geophysics, 56, 1, 59-67.

Nimmer, R.E., Osiensky, J.L., Binley, A.M. and Williams, B.C. (2008): Three-dimensional effects causing artifacts in two-dimensional, cross-borehole, electrical imaging. Journal of Hydrology, 359, 1-2, 59-70.

Osemeikhian, J.E.A. and Asokhia, M.B. (1994): Applied Geophysics. Stamatas Services Ltd.

Pellerin, L. (2002): Applications of electrical and electromagnetic methods for environmental and geotechnical Investigations. Surveys in Geophysics, 23, 101-132.

Petersen, T. and al Hagry, S.A. (2009): Mapping root zones of small plants using surface and borehole resistivity tomography. Leading Edge, 28, 10, 1220-1224.

Pullammanappallil, S.K. and Louie, J.N. (1994): A Generalized Simulated-Annealing Optimization for Inversion of
First-Arrival Times. Bulletin of the Seismological Society of America, 84, 5, 1397-1409.

Qin, F., Luo, Y., Olsen, K., Cai, W. and Schuster, G.T. (1992): Finite-Difference Solution of the Eikonal Equation. Geophysics, 57, 478-487.

Reynolds, J.M. (2011): Electrical resistivity sounding and tomography. Technical summary Technical Summary. Reynolds International. 2, 2 p.

Rucker, D., Loke, M.H., Levitt, M.T., Noonan, G.E. (2010): Electrical resistivity characterization of an industrial site using long electrodes. Geophysics, 75, 4, WA95-WA104.

Schuster, G.T. and Quintus-Bosz, A. (1993): Wavepath Eikonal Traveltime Inversion: Theory. Geophysics, 58, 9, 1314-1323.

Seladji, S., Cosenza, P., Tabbagh, A., Ranger, J. and Richard, G. (2010): The effect of compaction on soil electrical resistivity: a laboratory investigation. European Journal of Soil Science, 61, 1043-1055.

Sheehan, J.R., Doll, W.E., and Mandell, W.A. (2005b): An Evaluation of Methods and available Software for Seismic Refraction Tomography Analysis. Journal of Environmental and Engineering Geophysics, 10, 1, 21-34.

Singer, B.S. and Strack, K.M. (1998): New aspects of throughcasing resistivity theory. Geophysics, 63, 1, 52-63.

Sorensen, K.I. (1996): Pulled Array Continuous Profilling. First Break, 14, 85-90.

Steeples, D.W. (2001): Engineering and environmental geophysics at the millennium. Geophysics, 66, 31-35.

Stefani, J.P. (1995): Turning-ray tomography, Geophysics, 60, 1917-1929.

Storz, H., Storz, W. and Jacobs, F. (2000): Electrical resistivity tomography to investigate geological structures of the Earth's upper crust. Geophysical Prospecting, 48, 3, 455-471.

Tabbagh, A., Dabas, M., Hesse, A. and Panissod, C. (2000): Soil resistivity: a non-invasive tool to map soil structure horizonation. Geoderma, 97, 393-404.

Tong, C.H., Lana, C., Marangoni, Y.R. and Elis, V.R. (2010): Geoelectric evidence for centripetal resurge of impact melt and breccias over central uplift of Araguainha impact structure. Geology, 38, 91-94.

Tsokas, G.N., Tsourlos, P.I., Vargemezis, G.N. and Pazaras, N.T. (2011): Using surface and cross-hole resistivity tomography in an urban environment: an example of imaging the foundations of the ancient wall in Thessaloniki, North Greece. Physics and Chemistry of the Earth, 36, 16, 1310-1317.

Vidale, J.E. (1988): Finite Difference Calculation of Travel Times. Bulletin of the Seismological Society of America, 78, 2062-2076.

Wilkinson, P.B., Chambers, J.E., Meldrum, P.I., Ogilvy, R.D. and Caunt, S. (2006): Optimization of array configurations and panel combinations for the detection and imaging of abandoned mineshafts using 3D cross-hole electrical resistivity tomography. Journal of Environmental and Engineering Geophysics, 11, 3, 213-221.

Wilkinson, P.B., Loke, M.H., Meldrum, P.I., Chambers, J.E., Kuras, O., Gunn, D.A. and Ogilvy, R.D., (2012): Practical 
aspects of applied optimized survey design for electrical resistivity tomography. Geophysical Journal International, 189, 1, 428-440.

$\mathrm{Xu}, \mathrm{B}$. and Noel, M. (1993): On the completeness of data sets with multi-electrode systems for electrical resistivity survey. Geophysical Prospecting, 41, 791-801.

Zhang, J. and Toksoz, M.N. (1998): Nonlinear Refraction Travel-time Tomography. Society of Exploration Geophysicists. Geophysics, 63, 5, 1726-1737.

Zhou, B. and Dahlin, T. (2003): Properties and effects of measurement errors on $2 \mathrm{D}$ resistivity imagine survey. Near surface geophysics, 1, 3, 105-117.

Zhu, X. and McMechan, G.A. (1989): Estimation of two-dimensional seismic compressional wave velocity distribution by interactive tomographic imaging, International Journal of Image System Technology, 1, 13-17.

\section{Books/Theses:}

ABEM (2009): Terrameter SAS4000/SAS1000 LUND Imaging System Instruction Manual. ABEM Instrument AB, Sundbyberg, Sweden. No. 93109, 148 p.

Akingboye, A.S. (2018): Two-Dimensional Geoelectrical Subsurface Classification of Etioro-Akoko Area, Ondo State, Southwestern Nigeria. Unpublished MSc Dissertation, Department of Earth Sciences, Adekunle Ajasin University, Akungba-Akoko, Ondo State, Nigeria. 110 p.

Burger, H.T., Sheehan, A.F. and Jones, C.H. (2006): Introduction to Applied Geophysics: Exploring the Shallow Subsurface. W.W. Norton \& Company, London.

Everett, M.E. (2013): Near-Surface Applied Geophysics. Cambridge University Press, Edinburgh Building, Cambridge, UK. $441 \mathrm{p}$.

Ewusi, A. (2006): Groundwater Exploration and Management using Geophysics: Northern Region of Ghana. International Course of Study: Environmental and Resource management. PhD Thesis, Faculty of Environmental Sciences and Process Engineering, Brandenburg Technical University of Cottbus. $186 \mathrm{p}$.

Gibson, P.J. and George, M.D. (2003): Environmental Applications of Geophysical Surveying Techniques. Nova Science Publishers. Hauppauge, New York, USA.

Intelligent Resources Inc. (2006): Rayfract version 2.64 User's Manual and Software for Windows.

Kearey, P., Brooks, M., and Hill, I. (2002): An introduction to geophysical exploration ( $3^{\text {rd }}$ ed.). Blackwell Publishing, Malden, U.S.A. 281 p.

Loke, M.H. (1994): The inversion of two-dimensional resistivity data. Unpubl. $\mathrm{PhD}$ thesis, University of Birmingham.

Loke, M.H. (2002): Electrical imaging surveys for environmental and engineering studies: A practical guide to 2-D and 3-D surveys. $127 \mathrm{p}$.

Loke, M.H. (2004): Rapid 2-D resistivity and IP inversion using the least-square method. Manual for RES2DINV version 3.54. $53 \mathrm{p}$.

Merritt, A.J. (2014): 4D Geophysical Monitoring of Hydrogeology Precursors to Landslide Activation. PhD Thesis, School of Earth and Environmental, University of Leeds, UK. 276 p.
Quigley, P.T. (2006): Ground proving Seismic Refraction Tomography (SRT) in laterally variable Karstic Limestone Terrain. M.Eng. Thesis. University of Florida. 143 p.

Reynolds, J.M. 1997. An Introduction to Applied and Environmental Geophysics. John Willey \& Sons, England.796 p.

Silvester, P.P. and Ferrari, R.L. (1990): Finite elements for electrical engineers ( $2^{\text {nd }}$ ed.). Cambridge University Press.

Telford, W.M., Geldart, L.P., Sheriff, R.E., Keys, D.A. (1990): Applied Geophysics. Cambridge University Press. 744p.

Tsourlos, P. (1995): Modelling interpretation and inversion of multi-electrode resistivity survey data, Ph.D. thesis, University of York.

\section{Chapters in books or proceedings with editor(s):}

Advanced Geosciences Incorporated (AGI) (2008): Workshop/Seminar on Resistivity Imagining. Austin, April 29.

Bauman, P. (2005): 2-D resistivity surveying for hydrocarbons - a primer. CSEG Recorder. 25-33

Carpenter, P.J., Higuera-Diaz, I.C., Thompson, M.D., Atre, S. and Mandell, W. (2003): Accuracy of Seismic Refraction Tomography Codes at Karst Sites, Geophysical Site Characterization: Seeing beneath the Surface. Proceedings of a Symposium on the Application of Geophysics to Engineering and Environmental Problems, San Antonio. 832-840.

Chambers, J.E., Gunn, D.A., Meldrum, P.I., Wilkinson, P.B., Ogilvy, R.D., Haslam, E., Holyoake, S. and Wragg, J. (2011): Volumetric imaging of earth embankment internal structure and moisture movement as a tool for condition monitoring. $11^{\text {th }}$ International Conference and Exhibition, University of Westminster, London, UK, June 29-30.

Cosentini, R.M., Della Vecchia G., Foti, S. and Musso G. (2011): Detecting water content changes in sand samples by means of Electrical Resistivity Tomography. Unsaturated Soils. Alonso \& Gens (eds.), Taylor and Francis Group, London.

Cramer, B.J. and Hiltunen, D.R. (2004): Investigation of Bridge Foundation Sites in Karst Terrane via Seismic Refraction Tomography. 83 ${ }^{\text {rd }}$ Annual Meeting Compendium of Papers CD-ROM, Transportation Research Board, Washington, D.C., January 11-15.

Gunn, D. A., Ogilvy, R., Chambers, J. and Meldrum, P. (2010): ALERT-ME New technologies for embankment warning systems. Rail Technology Magazine, Oct/Nov. 80-82.

Hiltunen D.R. and Cramer, B.J. (2006): Geophysical Characterization of Bridge Foundation Sites in Karst Terrane, $85^{\text {th }}$ Annual Meeting Compendium of Papers CD-ROM, Transportation Research Board, Washington DC, January 22-26.

Mwenifumbo, C.J. (1997): Electrical methods for ore body delineation. Proceedings of Exploration: Fourth Decennial International Conference on Mineral Exploration, A.G. Gubbins (ed.). 667-676.

Pazdirek, O and Blaha, V. (1996): Examples of resistivity imagine using ME-100 resistivity field acquisition system. $58^{\text {th }}$ EAGE conference and technical exhibition extended abstract, Amsterdam.

Sheehan, J., Doll, W., Watson, D.B. and Mandell, W. (2005a): Application of Seismic Refraction Tomography to Karst 
Cavities. U.S. Geological Survey Karst Interest Group Proceedings. Rapid City, South Dakota, September 12-15. 29-33.

Society of Exploration Geophysicist (SEG) (2004): Application of Geophysical Methods to Engineering and Environmental Problems. Society of Exploration Geophysicist, Tokyo, Japan.

Stummer, P. and Maurer, H.R. (2001): Real-time experimental design applied to high-resolution direct-current resistivity surveys. International Symposium on Optical Science and Technology, Expanded Abstracts. 143-150.

Tien-When, L., Philips, L. (1994): Fundamentals of seismic tomography. Geophysical Monograph Series; no. 6, Society of Exploration Geophysicists. 6, 178 p.

\section{Report:}

Gregory, S.B. (2002): Near-surface seismic refraction tomography tutorial. UB Geophysics Report.

\section{SAŽETAK}

\section{Pregled tehnika seizmičke refrakcije i tomografije električnom otpornošću u istraživanju podzemlja}

Geofizičko istraživanje podzemlja temelji se na fizikalnim načelima kojima se objašnjava intrinistička priroda geoloških pojava. Tijekom zadnja dva desetljeća primjena seizmičke refrakcijske tomografije (skr. SRT) te one električne otpornosti (skr. ERT) značajno je povećala kvalitetu 2D i 3D interpretacije prikupljenih podataka. Tehnika SRT-a rabi veći broj točaka i prijamnika negoli konvencionalna seizmička refrakcija. Tehnika ERT-a koristi automatizirane višeelektrodne nizove s ciljem prikupljanja većega broja podataka na manjoj površini. Obje se temelje na naprednim algoritmima inverzije kako bi omogućile stvaranje visokorazlučivih modela podzemlja na kojima je moguće interpretirati složene geološke odnose. Stoga je primjena takvih 2D i 3D modela višestruka; za određivanje granica podzemnih tijela ili promjena $\mathrm{u}$ njima, opažanja podzemnih voda, rješavanje inženjersko-geoloških problema, u rudarskim istraživanjima itsl. Ova studija je obuhvatila teorijske osnove tih tehnika te nekoliko primjera njihove uporabe.

\section{Ključne riječi:}

seizmička refrakcijska tomogrfija (SRT), tomografija električnom otpornošću (ERT), istraživanje podzemlja, višeelektrodni niz, inverzijski model.

\section{Authors' contribution}

Adedibu Sunny Akingboye (M.Sc. Applied Geophysics) gathered the necessary data and prepared the framework for write-up, including graphical. Abimbola Chris Ogunyele (M.Sc. Petrology and Geochemistry) was also involved in data gathering and writing. 